\title{
The development of sentence-interpretation strategies in monolingual German-learning children with and without specific language impairment*
}

KATRIN LINDNER

Abstract

Previous research on sentence comprehension conducted with German-learning children has concentrated on the role of case marking and word order in typically developing children. This paper compares the performance of German-learning children with language impairment (age 4-6 years) and without language impairment (aged 2-6, 8-9 years) in two experiments that systematically vary the cues animacy, case marking, word order, and subject-verb agreement. The two experiments differ with regard to the choice of case marking: in the first it is distinct but in the second it is neutralized. The theoretical framework is the competition model developed by Bates and MacWhinney and their collaborators, a variant of the parallel distributed processing models. It is hypothesized that children of either population first appreciate the cue animacy that can be processed locally, that is, "on the spot," before they turn to more distributed cues leading ultimately up to subject-verb agreement, which presupposes the comparison of various constituents before an interpretation can be established. Thus agreement is more "costly" in processing than animacy or the (more) local cue initial NP. In experiment I with unambiguous case markers it is shown that the typically developing children proceed from animacy to the nominative (predominantly in coalition with the initial NP) to agreement, while in the second experiment with ambiguous case markers these children turn from animacy to the initial NP and then to agreement. The impaired children also progress from local to distributed cues. Yet, in contrast to the control group, they do not acknowledge the nominative in coalition with the initial NP in the first experiment but only in support of agreement. However, although they do not seem to appreciate distinct case markers to any large extent in the first experiment, they are irritated if such distinctions are lacking: in experiment II all impaired children turn to animacy (some in coalition with the initial NP and/or particular word orders). In the discussion, the relationship between short-term memory and processing as 


\section{K. Lindner}

well as the relationship between production and comprehension of case markers and agreement are addressed. Further research is needed to explore in more detail "cue costs" in sentence comprehension.

\section{Introduction}

Language comprehension is an interactive process during which the listener derives the meaning of the utterance from phonetic-auditory, grammatical, and contextual information. Very young children tend to interpret utterances according to their knowledge of the world or to event probability (Chapman and Kohn 1978; Strohner and Nelson 1974). A number of cross-linguistic investigations have explored when children start to utilize grammatical information. Most of these studies presented sentences with a transitive verb asking the children to identify the agent. It was found that by age two to three children start to use grammatical information of the language they learn: English children tend to use word order by age 2;6 to 3 (e.g. Bates et al. 1984; Thal and Flores 2001) while Turkish children (at an even earlier age) and Hebrew children orient toward case markers; thus children exploit morphological markers before word order, if the markers are reliable (Slobin 1981; Slobin and Bever 1982; Weist 1983).

How do children with specific language impairment (abbr. SLI) perform in such a comprehension task? Children with this diagnosis have problems in producing grammatical sentences and, to a varying degree, comprehending them (cf. Bishop 1979, 1997 for a review). Children's interpretation strategies differ with regard to the degree of severity in comprehension problems. Evans and MacWhinney (1999) studied sevento eight-year-olds: the children with severe receptive problems used animacy as a cue for the agent while their peers with good receptive abilities (as well as the typically developing controls) preferred the first noun. Bishop (1982), van der Lely and Harris (1990), van der Lely (1994), and O'Hara and Johnston (1997) demonstrated that school children have difficulties with word-order cues when mapping thematic roles onto syntactic functions in reversible sentences or those with a double object.

This study explores the strategies German-learning children choose in interpreting sentences. German is a language with relatively free word order and some inflection. Yet, due to syncretism and homonymy, these morphological markers are not very reliable (cf. section 2.1). For instance, with regard to marking the nominative and accusative, only the markers for masculine singular nominative-accusative are contrastive while those for feminine and neuter nouns in the singular are homonymous. Two 
studies have investigated the strategies of normally developing children when identifying the agent in NVN sentences with case markers. Mills (1977) found with children aged five to eight that an unambiguous marker for the accusative in initial position blocks a word-order strategy, but the latter is used if the case marker on the first and the second NP cannot be distinguished (cf. also Slobin 1981). However, in a similar experiment with three- to five-year-old children, Schaner-Wolles (1989) did not find support for the "first NP-as-agent strategy." 1 While the three-year-olds interpreted active OVS sentences with an unambiguous marker at chance level (52\%), the four-year-olds were correct at $61 \%$ and the five-year-olds at $89 \%$. In contrast, with an ambiguous accusative marker children performed at random $(44 \%-50 \%)$. Schaner-Wolles (1989) suggests that children's knowledge about the finite verb in second position blocks the application of a "first-NP-as-agent strategy." Once they have acquired this verb position - around age three - they know that the position before the finite verb, the prefield, is not reserved for the subject. Since thematic roles are mapped onto morphological cases, word order is free to fulfil pragmatic needs. When children hear ambiguous markers they resort to a pragmatic strategy, the contextually most neutral one being "subject first."

This paper reexamines the degree to which German children rely on word order or case marking in interpreting the agent of a sentence. In addition, the current study (a) also examines the roles played by subject-verb agreement and animacy and (b) compares the comprehension skills of children with and without language impairment. Moreover, (c), the theoretical framework is the competition model, which has been used in a number of cross-linguistic studies with normal children and for one study with late talkers (Thal and Flores 2001) ${ }^{2}$ and one with language-impaired children (Evans and MacWhinney 1999).

The paper is organized in the following way: section 2 provides a brief outline of the theoretical framework leading to the hypotheses to be examined. Section 3 describes the participants, the experimental design, and the procedure. Section 4 reports the results, which will be discussed in section 5 .

\section{The theoretical framework: the competition model}

The competition model (e.g. Bates and MacWhinney 1982, 1989; MacWhinney 1987) belongs to the category of "interactive activation models." It is considered a variant of the parallel distributed processing models. Phonetic-phonological, morphologic, semantic, syntactic, and 
pragmatic information are activated in parallel, support each other, or compete with one another until one type of information or cue wins out. These competitions (or coalitions) of information work in both production and comprehension. Language is seen as a knowledge system that represents these kinds of information in terms of connections or associations between lexical items. This network is organized in the representational structures of the lexicon (cf. MacWhinnney 1987). Thus a lexical item like the verb schubsen 'to push' is associated with particular concepts and semantic properties, with particular auditory (in comprehension) or articulatory features (in production), with particular morphological features (e.g. with regard to paradigms), and, last but not least, via its valency it is related to particular arguments and their thematic roles; each set of particular features, concepts, or properties in turn is linked to sets of other features, concepts, or properties.

In the competition model - as in other functional grammars - forms are mapped onto functions. However, in this model, mapping is not $1: 1$, rather it is a many-to-many or one-to-many mapping. For instance, the thematic role "agent" in German may have the following cues: nominative, subject-verb agreement, animacy, and/or initial position in unmarked word order (NVN). The basic underlying principle of competition is that language does not tolerate a situation (for long) where two different forms express exactly the same meaning (cf. also the "principle of uniqueness" of Pinker 1987). In the learning process the competition model allows for some free variation of forms for a particular function at the boundaries between forms or in those areas where the cues governing competition have not yet been discovered (MacWhinney 1987: 291).

A cue may be considered more or less valid in pointing to a particular function. Its validity can be calculated on the basis of its availability, its presence relative to the total number of instances where it might be present, and its reliability, that is, the number of opportunities in which an available cue points reliably to a particular function relative to its total cases of availability; cue validity then is the product of the cue's availability and reliability (e.g. McDonald 1989). ${ }^{3}$ For instance, as a positional cue for "subject," the preverbal position is high in validity in English, but low in Italian.

One assumption of the competition model is that language users and therefore also language learners are sensitive toward the statistical properties of their language. Thus in processing they not only perceive the information value of a particular cue in pointing to a particular function, but they also continually update the associations between forms and functions. Thus users/learners continually adapt cue strength, that is, the 
weight of such connections. In this way learning a language is intimately connected to processing the relevant information.

However, processing/learning may be influenced by two factors that need to be taken into account: cue cost and conflict reliability. It is generally held that a valid cue is learned with greatest ease. Yet the validity of a cue may be impeded by "processing cost" or "cue cost": for instance a cue may be difficult to detect, such as the accusative marker - $t$ in Hungarian added to a word ending in a fricative (as in mokus- $t$ 'squirrel'; cf. MacWhinney et al. 1985), or it may be costly in terms of great demands on working memory (see below). Furthermore, McDonald (1986) found that for more competent speakers, particularly adults, it is not so much overall validity that matters but rather conflict reliability or conflict validity: that is, if two cues are both reliable in pointing to a particular function, that cue is assigned conflict validity that wins out in the competition. In (1) animacy is in conflict with the positional cue first NP:

(1) Die Bürste streichelt die Katze.

'The brush strokes the cat.'

How valid are case and agreement markers as well as word order as cues to sentence interpretation in German?

\subsection{Cue validity and cue cost, local and distributed cues in German}

In German, case is marked primarily on the articles (as well as on attributive adjectives) since nouns have lost most of the case distinctions. The inflectional suffixes include information on number, gender, and case. With regard to the relevant contrast for this investigation, the nominative and accusative, only singular masculine nominative-accusative is reliable (e.g. der Mann= NOM vs. den Mann= ACC), because both feminine and neuter nouns in the singular as well as all plural forms neutralize case distinctions; see (2).

(2) a. Der Mann umarmt die Frau und das Kind. the-NOM man hugs the-ACC woman and the-ACC child

b. Die Frau und das Kind umarmen den Mann. the-NOM woman and the NOM child hug the-ACC man

c. Die Männer umarmen die Frauen und die the-NOM men hug the-ACC women and the-ACC Kinder. children 
d. Die Frauen und die Kinder umarmen die the-NOM women and the-NOM children hug the-ACC Männer.

men

Regarding agreement, German verb inflection marks person and number. Yet here too there is not much reliability in the verb suffixes for the present tense: except for the 1st and 2nd person singular, which are distinct (ich spiele/du spielst 'I play/you play') the 1st and 3rd person plural as well as the 3 rd person singular masculine, feminine, and neuter and the 2nd person plural are homonymous. (wir/sie spielen vs. er/sie/es/ihr spielt 'we/they play' vs. 'he/she/it/plays, you play'). The contrast relevant in this investigation will be the 3rd person singular and plural (er/sie/es spielt vs. sie spielen).

As for word order, German is a language with relatively free word order. Thus, in contrast to English for instance, the accusative may be topicalized (cf. [3b]). Moreover, there are also three positions for the finite verb that need to be differentiated: the initial position for imperatives and yes-no questions (as in [3a]), the second position for declarative sentences (as in [3b]) and the final position in clauses with a complementizer (as in $[3 \mathrm{c}]$ ).

(3) a. Yes-no questions (also imperatives etc).

Streichelt der Mann den Hund?

pats the-NOM man the-ACC dog

'Does the man pat the dog?'

vs.

Streichelt den Hund der Mann? ${ }^{4}$

pats he-ACC dog the-NOM man

'Does the man pat the dog?'

b. Declaratives

Der Mann streichelt den Hund.

the-NOM man pats the-ACC dog.

vs.

Den (')Hund streichelt der (')Mann.

the-ACC dog pats the-NOM man

'It is the dog whom the man pats.'

'It is the man who pats the dog.'

c. Desideratives (also imperatives) ${ }^{5}$

Wenn der Mann (doch einmal) den Hund streichelte! if the-NOM man (only once) the-ACC dog would pat 'If the man would pat the dog only once.' 
(3c) shows, furthermore, that the finite verb is not always adjacent to the subject but may occur at some distance from it (cf. also [4]). The sentence types in (3) thus indicate that children learning German will become familiar with the three different word orders in matrix clauses VNN, NVN, and NNV.

One way to evaluate cue validity has been to use text counts. Kempe and MacWhinney (1998: 551) have calculated the validity of cues for an agent in German on the basis of 671 sentences with a transitive verb requiring an agent and a patient. ${ }^{6}$ They found that the positional cue first NP is the most valid one, reaching 0.891 . It is followed by animacy contrast with 0.770 , and case-marking total with 0.653 , which is slightly above subject-verb agreement with 0.652 . The last cue of interest here is the nominative, which reached 0.467 . Given this hierarchy for German the positional cue is the most valid cue, followed by animacy contrast, subject-verb agreement, and then the nominative or citation form.

However, as mentioned above, the validity of a particular cue may be impeded due to cue cost. With regard to processing limitations Ammon and Slobin (1979) as well as Kail and Charvillat (1988) have distinguished local from distributed or topological cues.

Local processing refers to the identification and interpretation of a cue within one lexical word without considering other words within the clause. [...] Topological processing refers to the identification and interpretation of cues coded across words (Kail and Charvillat 1988: 638f.).

A local cue may be interpreted "on the spot" and is less costly than a topological or distributed cue, which has to be stored and compared and therefore makes more demands on short-term memory before it can be evaluated. In German, a local cue is the lexical-semantic cue animacy, while a distributed cue is subject-verb agreement, where a number of constituents may have to be processed before it can be established; see (4):

(4) Und dann betrat endlich nach drei Stunden der Präsident and then entered at last after three hours the-NOM president den Raum.

the room

'And then at last, after three hours, the president entered the room.'

In terms of local and distributed cues the following scale seems to be appropriate for German:

(5) Local and distributed cues in German

local distributed

animacy $>$ case: nominative $>$ subject-verb agreement

1.NP 'NP relative to (finite) $\mathrm{V}$ '


As mentioned before, animacy is more local than the NP citation form and agreement is more distributed than the NP nominative (comprising one or two words). Regarding positional cues a "first NP" strategy requires more local processing, while the utilization of an NP and V or both NPs presupposes more distributed processing.

\subsection{Hypotheses}

This paper examines the strategies in sentence comprehension used by children learning German as their first language. More specifically it examines whether German children start out by processing local cues and then proceed to topological cues, as has been observed for children learning other languages like French or Spanish (e.g. Kail and Charvillat 1988). On the basis of the progression in (5) the following hypotheses are set up for the typically developing children (typically developing, abbr. TD):

(H1 TD) In sentence interpretation typically developing Germanlearning monolingual children proceed from local cues to distributed cues.

The sequence will be specified in more detail in (H2 TD) and (H3 TD).

In addition, this paper compares the performance of typically developing children with language-impaired children. Given the findings about English children with specific language impairment in section 1, we may expect that these children do not perform at the same level as their typically developing peers. Indeed, the English-speaking children with SLI seem to adhere to less-complex strategies like local processing on the lexical-semantic level or on the syntactic level. German-learning children, however, are acquiring a language that is morphologically richer than English. Although German-learning children with SLI are known for their difficulties in producing case and agreement markers, ${ }^{7}$ Lindner and Johnston (1992) found that they are relatively more proficient learners of morphological forms than English-learning children with SLI.

Thus there are two issues that need to be considered:

i. What is the relationship between production and comprehension? Can we safely assume a 1:1 relationship between production and comprehension? If yes, then on the basis of production data the German-learning children should have problems interpreting case and agreement markers but on the basis of cross-linguistic findings they should be (relatively) better in grammatical morphology than the English-learning children with SLI. 
The second issue is also rather fundamental for any investigation involving SLI children.

ii. Do language-impaired children develop in parallel to typically developing children? There has been considerable discussion about deviant versus delayed development in children with SLI. The latter has often been preferred for younger children, the former for schoolchildren. ${ }^{8}$ Since there are no findings about German-learning children concerning sentence-interpretation tasks of the sort investigated here, parallel development will be assumed.

Given language-specific sensitivity (Lindner and Johnston 1992) and the assumption about parallel development, the basic hypothesis will be that German children with SLI will also start out with local cues and move on to distributed cues. The hypothesis in (H1 TD) will thus be generalized and replaced by (H1 G) (with "G" as an abbreviation for "general").

(H1 G) General hypothesis

In sentence interpretation German-learning monolingual children with and without language impairment will orient first toward local and then toward distributed cues.

The hypotheses about the developmental course are spelled out in the following:

Hypotheses for the typically developing children:

(H2 TD) In the case of unambiguous case markers, typically developing German-learning monolingual children orient first toward animacy, then toward the nominative, and finally toward agreement.

(H3 TD) In the case of ambiguous case markers, typically developing German-learning monolingual children choose animacy, then a positional strategy "first NP," before they orient toward agreement.

The hypotheses for the children with SLI will be formulated in analogy to those for the typically developing children. To differentiate them, those for the language-impaired children will receive the abbreviation SLI.

Hypotheses for the children with SLI

(H2 SLI) In the case of unambiguous case markers, German-learning preschoolers with SLI orient first toward animacy, then toward the nominative, and finally toward agreement.

(H3 SLI) In the case of ambiguous case markers, German-learning preschoolers with SLI choose animacy, then a positional strategy "first NP," before they orient toward agreement. 
(H1 G) and the other hypotheses will be examined in two experiments: the first will employ case distinctions due to masculine nouns, the second will contain ambiguous case markers due to feminine nouns.

\section{Method}

\subsection{Participants}

The participants in these two experiments were monolingual Germans speaking a variety of the city dialect of Munich or Augsburg in Bavaria, Germany. Children's socioeconomic background was comparable.

The normally developing participants were 84 children aged 2;2-6;11, $8 ; 0-8 ; 11$, and 9;0-9;10, as well as adults, with twelve subjects in each age group, six female and six male. Their mean age was $2 ; 8,3 ; 6,4 ; 6,5 ; 6$, $6 ; 6,8 ; 6,9 ; 6 .{ }^{9}$ The adults, aged 19 to 31 years, were included to compare the children's performance to that of competent users. They were students in their last year of schooling before entering university, or they were enrolled in various faculties at the University of Munich.

The 23 children with specific language impairment were aged $4 ; 3-4 ; 11$, $5 ; 0-5 ; 9 ; 6 ; 2-6 ; 10$. There were eight five- and eight six-year-olds and seven four-year-olds (one four-year-old boy had to leave the project due to long-term illness). The children were selected according to the traditional criteria: an IQ within normal range (measured with the Columbia Mental Maturity Scale, Burgermeister et al. 1972), no hearing or vision impairment or social-emotional disturbance responsible for their language problems. Within each age group, four children were severely impaired (one girl, three boys), and four were lightly impaired (one girl and three boys, but two boys among the four-year-olds). The degree of severity in impairment was evaluated on the basis of children's achievements in a production test, test C of the Logopädische Sprachverständnistest (abbr. LSVT, Wettstein 1983); severely impaired children performed below the second percentile (2 SD), lightly impaired achieved scores between the eighth and second percentile (1-2 SD).

Of the children's other linguistic skills two will be mentioned here: all children from age three onward achieved scores within the normal range in a vocabulary-production test (Aktiver Wortschatztest, Kiese and Kozielski 1979). Furthermore, they all passed a standardized sentencecomprehension task comprising 17 sentences with increasing length and grammatical difficulty, test A of the LSVT (cf. Appendix). These sentences describe events dealing with everyday actions of a family, their dog, a 
bird, and a ball. The children were asked to act them out. All children performed within the normal range. ${ }^{10}$

With regard to the studies reported here one other test result is of interest: the children's performance in a short-term memory test ${ }^{11}$ (see Figure 1). There is a clear difference between the means of each age group for the control group and for the severely and the lightly impaired group. The performance of the latter two is clearly below that of their normal peers; that is, while the normal children, age five or six, were within their age norms (four or five items remembered) the SLI children of the same chronological age only remembered up to three items. Thus there is also a clear gap between the results of this short-term memory test and the standardized sentence-comprehension test.

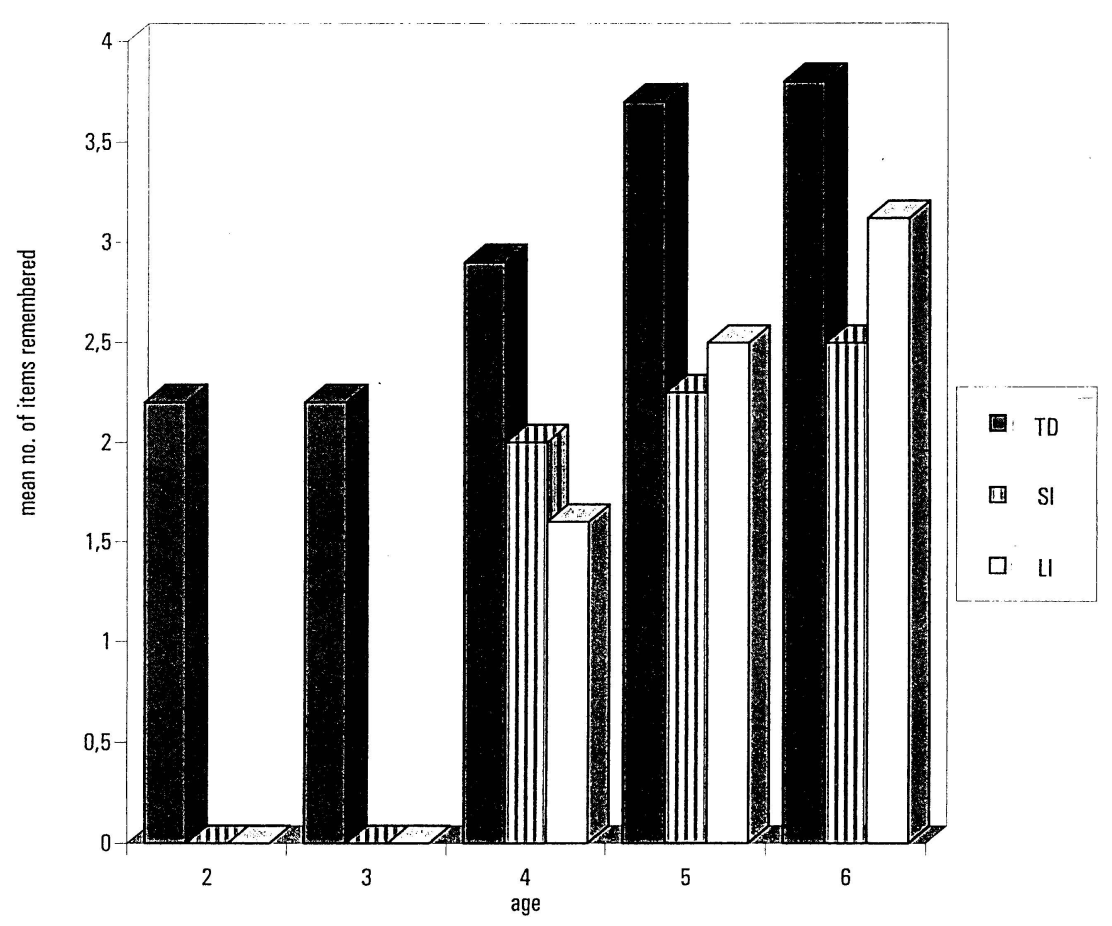

Figure 1. Results from the short-term memory test: mean number of items remembered by the three groups of children: typically developing (TD), lightly impaired (LI), and severely impaired children (SI) 


\subsection{Design and procedure}

The two experiments follow in design and procedure the experiments in the literature (e.g. Bates et al. 1987; MacWhinney and Bates 1989).

The first experiment comprised 81 sentences with a transitive verb, so that the arguments could be assigned to an agent and a patient. The variables were animacy, word order, case, and subject-verb agreement. Each variable had three values:

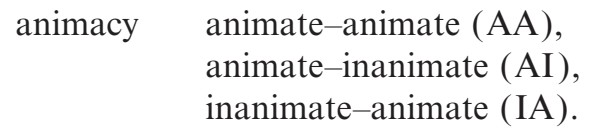

word order NVN,

NNV,

case $^{12}$ a nominative singular on the first NP (C1),

a nominative singular on the second $\mathrm{NP}(\mathrm{C} 2)$,

case marking is not unique $(\mathrm{C} 0)$

with one NP in the plural or both in the nominative singular (which in turn leads to AG0, see below).

agreement agreement with the first NP (AG1), agreement with the second NP (AG2)

agreement with either NPs in case of an ambiguous sentence (AG0).

The variable "case" makes sense only with masculine nouns. These were chosen in experiment I. The stimuli were of the following kind:

(6) a. (AA, NVN, C1, AG1)

Der Frosch schubst den Storch.

the-NOM frog pushes the-ACC stork

'The frog pushes the stork.'

b. (IA, NNV, C2, AG2)

Den Klotz der Frosch schubst.

the-ACC block the-NOM frog pushes

'The frog pushes the block.'

c (AI, VNN, C0 AG1)

Schubsen die Frösche den Klotz.

push the-NOM frogs the-ACC block

'The frogs push the block.'

d. (AA, NVN, C0, AG0)

Der Frosch schubst*der Storch.

the-NOM frog pushes *theNOM stork 


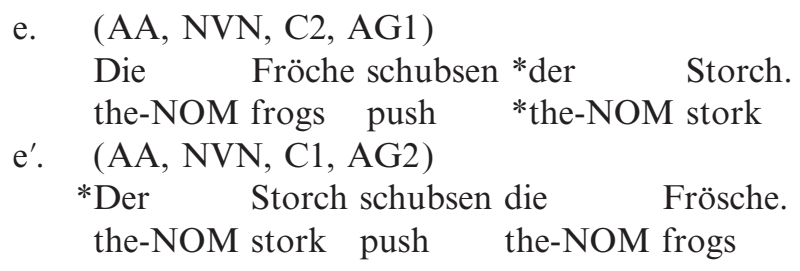

Sentences (6d), (6e), and (6e') are ungrammatical in German, because they each contain two nominatives. The reason for including these constructions was to observe children's choice of NP in the case of two possible candidates for agreement in (6d) and to examine their preference with conflicting cues for case and agreement as in $(6 \mathrm{e}) /\left(6 \mathrm{e}^{\prime}\right)$ with AG1 vs. $\mathrm{C} 2$ in (6e) and $\mathrm{AG} 2$ vs. $\mathrm{C} 1$ in $\left(6 \mathrm{e}^{\prime}\right)$.

The second experiment was made up of 54 sentences with transitive verbs. This time the nouns were feminine so that case was neutralized. The three remaining variables were animacy, word order, and agreement. Again they had three values; AG0 now was assigned to ambiguous sentences with both NPs being either in the singular or plural as in (6f) and $(6 \mathrm{~g})$. The stimuli were taken from the comparative study by Bates et al. (1987).

\section{(6) f. (AI, NVN, AG0) \\ Die Katzen schubsen die Taschen. \\ 'The cats push the bags.' \\ g. (AI, NVN, AG0) \\ Die Katze schubst die Tasche. \\ 'The cat pushes the bag.'}

For both experiments the procedure was the same. Each participant was tested individually in a room he or she was familiar with. The younger normal children as well as the children with SLI were first asked to name all the objects to make sure that they were familiar with them. The participant was presented with one sentence at a time. If he or she hesitated or did not understand, the sentence was repeated as often as necessary. Each sentence was pronounced with an unmarked intonation contour. Then the subject was asked to act the sentence out with the relevant small objects standing in front of him or her. These objects were plastic toy animals or other items like cups or bags, size $5 \times 5 \mathrm{~cm}$ mounted on a matchbox. Each object came in two kinds: as a single object and as two objects. While the participant acted out the sentence the experimenter noted down which object was chosen to be the agent. 


\section{Results}

In the analysis all data of the participants were included except those where the behavior did not allow for a unique assignment of the agent to the first or second NP. In the statistical analysis two methods for categorical data were employed in parallel: a parametric one - the logit analysis - and a nonparametric one - the tree-based analysis (cf. Clark and Pregibon 1991). The latter provides a procedure to detect structures in the data via cross-validation. The results are represented in classification trees with binary branches and subbranches. The length of each branch measured with respect to the y-axis is proportional to the importance of the split: long branches indicate that a substantial amount of heterogeneity (compare the notion of variance in parametric models) is explained by the split. Short branches indicate that the nodes created by the split are still relatively heterogeneous themselves. Figures $2-5$ provide summaries of these results for each variable and for each age group; for these summaries the length of the branches contributing to homogeneity have been added. However, in order to trace the individual performance as well and thus control for homogeneity within each age group, a second set of tree-based analyses was run; it added "child' as a fifth variable with the respective values $(\mathrm{a}-\mathrm{l}$ or $\mathrm{a}-\mathrm{h})$.

The findings of each experiment will be reported for each age group starting with the unimpaired participants in experiment $\mathrm{I}$, then proceeding to the results for the impaired children before turning to the report of the findings in experiment II.

\subsection{Experiment $I$}

In this experiment the variables were animacy, word order, case and agreement. Case markers for singular nominative and accusative were distinct. If, as hypothesised in (H1 G), children orient first toward local cues and then toward distributed cues, then, according to the subsequent hypotheses (H2 TD) and (H2 SLI), children should start out with animacy, then turn to the nominative and finally to subject-verb agreement.

4.1.1. The findings for the typically developing participants. Figure 2 shows the findings for all age groups of the typically developing participants in this experiment. Clearly, for the two- and three-year-olds as a group animacy is the only important factor, while for the four-year-olds about two-thirds of the variance is explained by case - the nominative and one-third by agreement. Starting with age five up to age eight, case 


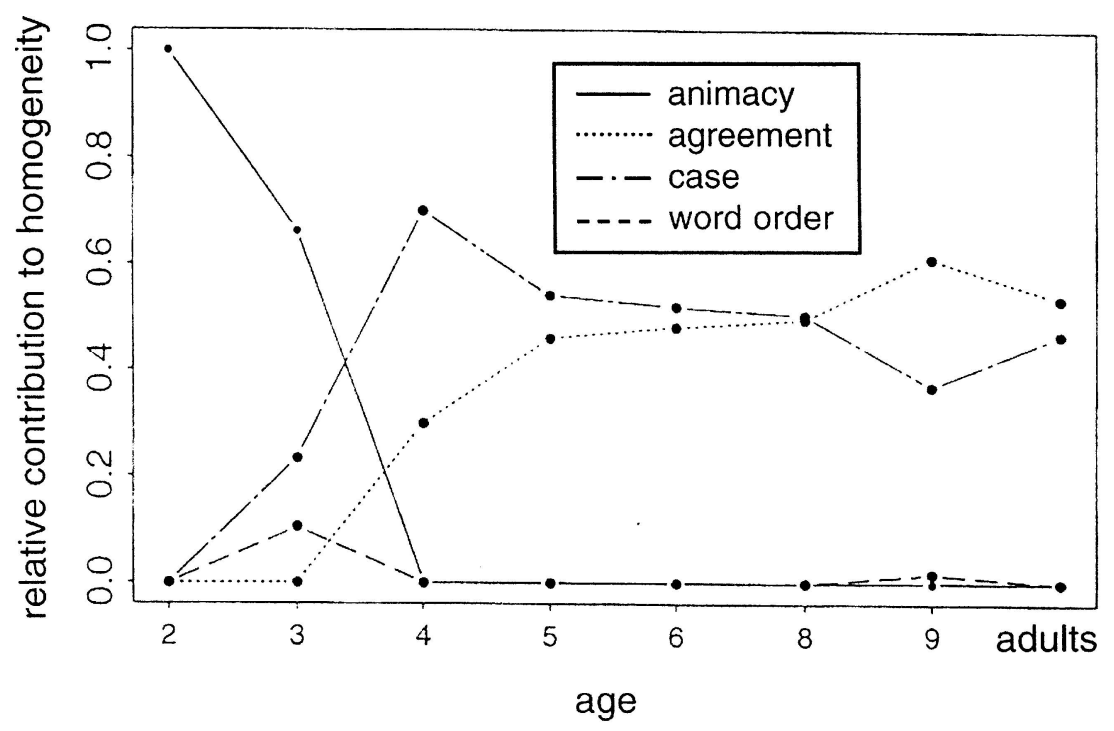

Figure 2. Relative contribution of animacy, agreement, case, and word order for all age groups of typically developing participants in experiment I

and agreement explain about $50 \%$ of the variance. Then agreement takes over for the nine-year-olds and decreases again for the adults.

Table 1 provides the results of the logit analysis for each variable. The level of significance was set at $p<0.001$. The tree-based analyses and the logit analysis confirm each other's results for the group data. ${ }^{13}$ The second set of tree-based analyses with the variable "child" provided more details about the behavior within each age group. Differentiation according to children did not start at the upper ends of the trees - which in turn confirms the group analyses - but at the level directly above or at the terminal nodes. Only a few details about children's behavior, in particular regarding competing cues, will be reported here. ${ }^{14}$

Among the twelve two-year-olds, five children orient strictly toward animacy, be it on the first or the second NP $(83 \%-90 \%)$, while five others prefer the initial NP at slightly above chance (56\%-57\%). Two children switch sides depending on the construction.

With the three-year-olds the picture changes slightly: only four out of twelve children still favor animacy over any other cue (80-90\%), while the other eight children are fairly undecided in case of an animate second NP contrasting with an inanimate first NP (IA 54\%). If animacy is in coalition with the initial NP and the nominative $(\mathrm{C} 1)$ all children choose that NP. However, if there is a conflict between animacy on the initial 
Table 1. Results of the logit analysis for the typically developing participants in experiment I

\begin{tabular}{|c|c|c|c|}
\hline Age groups & Main effects & $\mathrm{F}$ & $\mathrm{p}$ \\
\hline 2-year-olds & animacy & $\mathrm{F}(2,928)=86.24$ & $\mathrm{p}<0.001$ \\
\hline 3-year-olds & $\begin{array}{l}\text { animacy } \\
\text { animacy } \times \text { case } \\
\text { animacy } \times \text { word order }\end{array}$ & 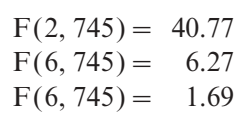 & $\begin{array}{l}\mathrm{p}<0.001 \\
\mathrm{p}<0.001 \\
\mathrm{p}<0.5, \text { n.s. }\end{array}$ \\
\hline 4-year-olds & $\begin{array}{l}\text { case } \\
\text { case } \times \text { agreement }\end{array}$ & $\begin{array}{l}\mathrm{F}(2,829)=48.37 \\
\mathrm{~F}(6,829)=13.91\end{array}$ & $\begin{array}{l}\mathrm{p}<0.001 \\
\mathrm{p}<0.001\end{array}$ \\
\hline 5-year-olds & $\begin{array}{l}\text { case } \\
\text { agreement } \\
\text { case } \times \text { agreement }\end{array}$ & $\begin{array}{l}\mathrm{F}(2,957)=99.72 \\
\mathrm{~F}(2,957)=83.65 \\
\mathrm{~F}(4,957)=38.96\end{array}$ & $\begin{array}{l}\mathrm{p}<0.001 \\
\mathrm{p}<0.001 \\
\mathrm{p}<0.001\end{array}$ \\
\hline 6-year-olds & $\begin{array}{l}\text { agreement } \\
\text { case } \\
\text { case } \times \text { agreement }\end{array}$ & $\begin{array}{l}\mathrm{F}(2,963)=197.28 \\
\mathrm{~F}(2,963)=160.29 \\
\mathrm{~F}(4,963)=33.43\end{array}$ & $\begin{array}{l}\mathrm{p}<0.001 \\
\mathrm{p}<0.001 \\
\mathrm{p}<0.001\end{array}$ \\
\hline 8-year-olds & $\begin{array}{l}\text { agreement } \\
\text { case } \\
\text { case } \times \text { agreement }\end{array}$ & $\begin{array}{l}\mathrm{F}(2,955)=213.09 \\
\mathrm{~F}(2,955)=201.29 \\
\mathrm{~F}(4,955)=44.90\end{array}$ & $\begin{array}{l}\mathrm{p}<0.001 \\
\mathrm{p}<0.001 \\
\mathrm{p}<0.001\end{array}$ \\
\hline 9-year-olds & $\begin{array}{l}\text { agreement } \\
\text { case } \\
\text { case } \times \text { agreement }\end{array}$ & $\begin{array}{l}\mathrm{F}(2,963)=332.95 \\
\mathrm{~F}(2,963)=149.51 \\
\mathrm{~F}(4,963)=39.02\end{array}$ & $\begin{array}{l}\mathrm{p}<0.001 \\
\mathrm{p}<0.001 \\
\mathrm{p}<0.001\end{array}$ \\
\hline Adults & $\begin{array}{l}\text { agreement } \\
\text { case } \\
\text { case } \times \text { agreement }\end{array}$ & $\begin{array}{l}\mathrm{F}(2,927)=504.50 \\
\mathrm{~F}(2,927)=340.40 \\
\mathrm{~F}(4,927)=53.61\end{array}$ & $\begin{array}{l}\mathrm{p}<0.001 \\
\mathrm{p}<0.001 \\
\mathrm{p}<0.001\end{array}$ \\
\hline
\end{tabular}

a. n.s. = nonsignificant.

NP and the nominative on the second NP (C2), all children show a slight tendency $(62 \%)$ toward the animate NP. Thus animacy is still the most important cue for these children.

The four-year-olds clearly go for the initial NP in coalition with the nominative $(\mathrm{C} 1) .{ }^{15}$ If the nominative is on the second NP (C2), four children choose it at chance $(57 \%)$, while the other eight prefer the initial NP $(76 \%)$. However, only one of these eight children takes the first NP (97\%) regardless of the distribution of any other cue.

Agreement comes into play among the five-year-olds; see Figure 2. If it is in coalition with the initial NP (AG1) all children choose the first NP. They also do so when there is a conflict between agreement (AG1) and the nominative pointing to the second NP (AG1 vs. C2). However, 
in the case of the opposite conflict (i.e. agreement with the second NP and nominative on the first NP, AG2 vs. $\mathrm{C} 1$ ) the nominative on the initial NP still wins out. A different behavior can be noted with regard to the combination of the nominative and agreement both pointing to the second NP: while seven children still prefer the first NP (67\%), the other five decide in favor of the second NP $(87 \%)$. Thus these five children acknowledge the initial accusative in sentences like Den Storch schubst der Frosch 'the-ACC stork pushes the-NOM frog' or in Die Störche schubst der Frosch 'the-ACC storks pushes the-NOM frog'. This is a big change in the appreciation of morphosyntactic cues compared to the performance of the younger age groups.

Among the six-year-olds the coalition of agreement and the nominative with the second NP (AG2/C2) leads 10 of 12 children to choose the second NP. Thus agreement is increasing in importance, when the nominative and agreement support each other. But if nominative and agreement are in conflict as in $(\mathrm{C} 1$ vs. AG2: *Der Storch schubsen die Frösche 'the-NOM stork push the-NOM frogs') six of them prefer the initial NP (91\%) and the other six are undecided (50\%). In the opposite conflict, that is, if agreement points to the first NP and the nominative to the second (AGl vs. C2), all children orient toward agreement $(73 \%$ ).

Among the eight-year-olds the trend continues to be in favor of the nominative and agreement in coalition with the second NP: nine of twelve children follow it. Yet in the case of conflicting cues (either C1 vs. AG2 or C2 vs. AG1) five children still take the first NP (96\%, 98\%) while seven are undecided $(50 \%, 51 \%)$.

For the nine-year-olds agreement wins out for the group, as was shown in Figure 2. With regard to the behavior of individual children the conflict between agreement and case is interesting. In the case of agreement pointing to the initial NP and the nominative to the second NP (AG1 vs. C2) the situation is even: six children decide in favor of agreement $(85 \%)$, the other six choose it at random $(52 \%)$. The latter group and one additional child, however, decide in favor of agreement (87\%) in the opposite case, that is, when agreement with the second NP competes with the nominative on the initial NP (C1 vs. AG2), while the other five show some preference for the initial nominative $(67 \%)$.

The adults also decide in favor of agreement. With conflicting cues (AG1 vs. $\mathrm{C} 2$ as well as with $\mathrm{AG} 2$ vs. $\mathrm{C} 1$ ) agreement wins, but again this is more pronounced for the second NP (AG2 7/12 at 87\%) than for the first NP (AG1 12/12 at 65\%). ${ }^{16}$

(H1 G) states that the typically developing participants in this experiment proceed from local to distributed cues. According to (H2 TD) they should start with lexical semantics and go on to grammatical markers, 
that is, the nominative and agreement. The findings confirm both ( $\mathrm{H} 1 \mathrm{G})$ and (H2 TD). The two-year-olds start out with animacy. Among the three-year-olds this cue is replaced gradually by the nominative in coalition with animacy and the first NP. The four-year-olds rely on the nominative in particular in coalition with the first NP. Yet there are also four children who start to acknowledge the nominative on the second NP (with 57\%). Around the age of five, when children start to rely on agreement, they also pay more and more attention to the combination of agreement and the nominative both pointing to the second NP. In this age group five children acknowledge the initial accusative in the singular and plural constructions, at age six to eight the number increases to nine or ten, and by age nine all the participants show this behavior (as did all the adults). Furthermore, by age nine it is agreement with the second NP that wins out over the nominative on the initial NP as the cue to the agent.

Clearly, when considering the performance of the individual children within this progression, the orientation toward the nominative for the four-year-olds is less strong than the group data would lead us to expect (cf. Figure 2). The nominative seems to be important in coalition with another cue, mostly with the initial NP. There is only one subgroup among the four-year-olds that shows a very slight preference for the nominative also on the second NP (57\%). When the nominative on the second NP competes with agreement with the initial NP (AG1 vs. C2), the nominative proves weaker with the five- and six-year-olds but causes roughly half of the eight- and nine-year-olds to choose at random. In the competition of the nominative on the first NP with agreement pointing to the second NP ( $\mathrm{C} 1$ vs. AG2), the nominative is chosen only by the five-year-olds, while six six-year-olds and seven eight-year-olds are undecided and seven nine-year-olds and seven adults decide against it. Thus, in conflicting constellations with agreement, $\mathrm{C} 1$ seems to lose importance and $\mathrm{C} 2$ seems to cause some irritation for the older age groups.

Among the younger age groups, age four to five or even six, the role of the initial NP is interesting, because it raises the question of a positional strategy. (H2 TD) does not make any prediction about a positional strategy with unambiguous case markers. Overall, there is only one fouryear-old who clearly adopts a positional strategy regardless of any other cue. Whether there may be more children who respond to the initial NP is not easy to determine since the positional cue is always in coalition with another cue that strengthens its value: namely with animacy for the three-year-olds, with the nominative for the four-year-olds, and/or with agreement for the five- and six-year-olds. One way to decide might be the competition between the initial NP and animacy or the nominative 
on the second NP: ${ }^{17}$ the majority of the four-year-olds decide in favor of the first NP (76\%) against the nominative on the second NP. This may, indeed, be an indication of a positional strategy for this age group. This strategy still appears to be available to the five- and six-year-olds, who prefer the initial NP (with its supporting cues) in case of competing morphosyntactic cues.

4.1.2. The findings for the language-impaired children The findings for the group data of the impaired preschoolers who participated in experiment I are shown in Figure 3. The youngest participants as a group prefer animacy as the most important cue for the agent. The next group, however, starts to take case and agreement into consideration. For the oldest group, agreement is the most important cue. This cue reaches $42 \%$, which is close to the value reached for agreement in the five- and sixyear-old controls (52-48\%). For the results of the logit analysis, consult Table 2. Again the two types of analysis for the group data confirm each other.

The second set of tree-based analyses outlines the preferences of the individual children. As before, the differentiation according to individual performance starts only at or shortly before the terminal nodes, so that these analyses support the other two as well.

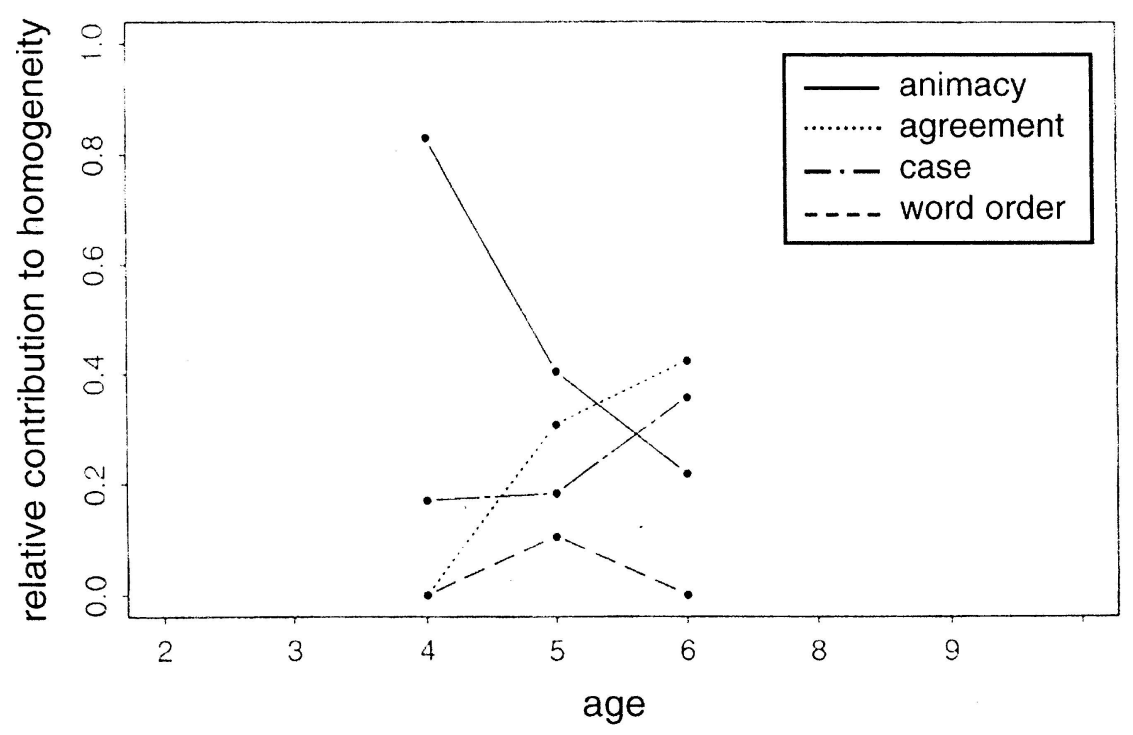

Figure 3. Relative contribution of animacy, agreement, case, and word order for all age groups of language-impaired children in experiment I 
Table 2. Results of the logit analysis for the language-impaired children in experiment I

\begin{tabular}{llll}
\hline Age groups & Main effects & $\mathrm{F}$ & $\mathrm{p}$ \\
\hline 4-year-olds & animacy & $\mathrm{F}(2,501)=22.77$ & $\mathrm{p}<0.001$ \\
& animacy $\times$ case & $\mathrm{F}(6,501)=2.31$ & $\mathrm{p}<0.05$ n.s. $^{\mathrm{a}}$ \\
& animacy & $\mathrm{F}(2,585)=20.23$ & $\mathrm{p}<0.001$ \\
5-year-olds & $\mathrm{F}(2,585)=9.42$ & $\mathrm{p}<0.001$ \\
& case & $\mathrm{F}(2,585)=8.13$ & $\mathrm{p}<0.001$ \\
& agreement & $\mathrm{F}(6,585)=2.14$ & $\mathrm{p}<0.05$, n.s. $^{\text {a }}$ \\
& ase $\times$ word order & $\mathrm{F}(2,615)=14.38$ & $\mathrm{p}<0.001$ \\
6-year-olds & animacy & $\mathrm{F}(2,615)=20.28$ & $\mathrm{p}<0.001$ \\
& case & $\mathrm{F}(2,615)=19.99$ & $\mathrm{p}<0.001$ \\
& agreement & $\mathrm{F}(4,615)=5.28$ & $\mathrm{p}<0.001$, n.s. $^{\mathrm{a}}$ \\
\hline
\end{tabular}

a. n.s. = nonsignificant.

Among the four-year-olds there are three subgroups: two children orient exclusively toward the animate NP; three prefer the initial NP in coalition with animacy and are undecided when an inanimate first NP is contrasted with an animate second (IA 55\%); and the last two children have a strong tendency to choose the first NP (one of them is a severely impaired child).

The five-year-old children with SLI decide in the following way: for sentences with an inanimate first NP and an animate second NP, three children still decide in favor of the animate NP (76\%; two of them are severely impaired), while the other five prefer the inanimate initial NP $(72 \%)$. In sentences with an animate first NP, animacy interacts with agreement (AG1) and word order on the one hand and with agreement (AG2) and case on the other. In the case of an animate initial NP supported by agreement (AG1), all children clearly choose the first animate NP in sentences with NVN and VNN and, with considerable interindividual variation, with NNV. The nominative only appears when agreement points to the second NP. If both cues support the second NP, this is chosen at about chance $(52 \%)$ by four five-year-olds, while the other four still orient toward the initial animate NP $(81 \%$, two of them severely impaired). If agreement and the nominative are in conflict $(\mathrm{C} 1$ vs. AG2), however, all five-year-olds overwhelmingly prefer the nominative, which, as mentioned before, is also supported by animacy.

The six-year-old impaired children are more homogeneous than the five-year-olds. The six-year-olds decide in favor of those NPs that are supported by both the nominative and agreement: thus they orient toward 
the first NP (89\%) in the case of AG1/C1 and toward the second NP $(59 \%)$ in the case of $\mathrm{AG} 2 / \mathrm{C} 2$. Yet, if the two cues are in conflict, as in the $\mathrm{C} 1$ vs. $\mathrm{AG} 2$ condition, the initial NP wins out for all children $(73 \%)$. In the opposite constellation - that is, with the nominative pointing to the second NP (AG1 vs. C2) - four children still prefer the first NP $(80 \%$, in coalition with the agreement cue and the positional cue), while the other four choose, at chance level, the nominative with the second NP (three of these children are severely impaired). This may be an indication that the nominative on the second NP is in fact detected by some six-year-olds.

Thus, in support of the general hypothesis (H1 G), the impaired children proceed from local to distributed cues, from animacy to morphosyntactic cues, as did the nonimpaired children. However, no support is found for (H2 SLI) that children with SLI pass through a transient stage in which they rely predominantly on the nominative for interpreting the agent. While the four-year-olds are concerned with animacy and/or the initial NP, neither five- nor six-year-olds are found to prefer the nominative (on the first NP or on the second NP) before they turn to agreement. However, when the nominative is in coalition with agreement, a subgroup of five-year-olds appears to take note if it is the second NP, and the six-year-olds do so regardless of whether it is the first or second NP. Thus these children seem to appreciate the coalition of both cues. There is only one small indication that the nominative is noticed: if agreement is with the first NP and the nominative is with the second NP (AG1 vs. C2), then $50 \%$ of the six-year-olds choose the nominative at chance level. ${ }^{18}$

As for agreement, this cue plays a role in sentence interpretation when it is supported by other cues: the five-year-olds prefer it along with the initial NP and animacy as well as in coalition with those word-order types where the first NP is closest to the finite verb, that is, NVN and VNN. Only a subgroup of five-year-olds chooses agreement with an inanimate second NP in coalition with the nominative at chance level and thus takes more note of grammatical cues. For the six-year-olds neither word order nor animacy seems to be of importance, but the coalition of agreement and the nominative with either the first or second NP remains. If the two cues are in conflict, agreement on the second NP (AG2) is not a decisive cue for any six-year-old, since $50 \%$ of these children do not turn to agreement with the first NP (AG1). Thus agreement is not yet a strong cue for this age group.

Finally, we will come to the possibility of a positional strategy. It was not predicted by (H2 SLI) that children with SLI would choose a positional strategy when case markers are unambiguous. However, this none- 
theless appears to be the case for two four-year-olds who took the initial NP regardless of other cues. All other children favor the first NP in coalition with other cues: with animacy, with the nominative, with agreement, and/or with word order. This is also evident in case of conflicting cues: when the nominative is in coalition with the initial NP and competing against agreement on the second NP, the six- and the five-year-olds prefer the initial NP in coalition with the nominative (which, moreover, for the five-year-olds, is also supported by animacy).

\subsubsection{Summary of the findings in experiment I: differences and} similarities. In the first experiment the general hypothesis (H1 G) and its specification were tested. It was hypothesized that, in the case of distinct case markers, German-learning participants with and without impairment proceed from local to distributed cues. (H1 G) was confirmed for all groups.

Its specification in (H2 TD) was confirmed for the typically developing participants. Among the youngest children animacy is preferred, around age four the nominative is chosen, in particular in coalition with the initial NP but for a subgroup also with the second NP. From age five onward children orient toward agreement - in particular if the nominative supports agreement. But, with age, the nominative seems to decline in importance compared to agreement, as demonstrated with the older participants.

The impaired children, too, start out with animacy and, with age, make use of agreement, particularly in coalition with the nominative, thus supporting the general hypothesis (H1 G). However, no support was given to (H2 SLI), which posits an intermediate phase during which children with SLI orient toward the nominative before they turn to agreement. Rather, it was found that the two morphoyntactic cues seem to be relied on at about the same time by the five-year-olds and more so by the six-year-olds.

Thus, in the first experiment it was found that children with and without impairment differ with regard to their use of the nominative and agreement as cues to the agent: while the typically developing children rely on the nominative before they turn to agreement, the impaired children seem to orient toward both cues at about the same time. It is only later, by age six, that some of the children differentiate between the two cues. Furthermore, there is an interesting distinction in preference between the six-year-old impaired children and their typically developing peers when the nominative and agreement are in competition: while the normally developing children prefer agreement on the initial NP in the condition in which agreement with the first noun competes with the 
nominative on the second noun (AG1 vs. C2), of the impaired group $50 \%$ are undecided. The opposite holds for the condition in which the nominative on the initial NP competes with agreement with the second $\mathrm{NP}(\mathrm{C} 1$ vs. $\mathrm{AG} 2)$ : here the impaired children choose the initial NP, while $50 \%$ of the normal children are undecided. Thus the normal six-yearolds seem to attend more to agreement while the impaired six-year-olds seem to attend more toward the nominative. This issue needs further in-depth analysis of the individual performances.

Another major difference between the normal and the impaired children is their appreciation of animacy: for the typically developing children, animacy ceases to be important by age four. With the impaired children, however, this stage is reached by age six. Thus the normal children turn to grammatical cues about two years earlier than the impaired children.

Despite these differences there are also a few similarities between the two groups. To mention just a few: a subgroup of the normal five-yearolds is the first to acknowledge agreement on the second NP (87\%) supported by the nominative. Although less impressive in percentages (only $52 \%$ ), an indication of a similar behavior can be observed in a subgroup of impaired five-year-olds. Furthermore, six-year-olds with and without impairment prefer such coalitions between agreement and the nominative. With regard to conflicting cues the five-year-olds also seem to act alike, choosing the initial NP when the nominative on the first NP is in conflict with agreement pointing to the second (C1 vs. AG2). Last but not least, in both populations there are children who favor the initial NP regardless of any other cue: one typically developing, one severely impaired, and one lightly impaired child. A positional strategy may also be a more or less hidden strategy for other normal four-year-olds (cf. section 4.1.1) and older subgroups, particularly when confronted with competing morphosyntactic cues.

\subsection{Experiment II}

The second experiment dealt with sentences in which case is neutralized through the use of feminine nouns, which, unlike masculine nouns, do not mark the distinction between nominative and accusative singular in German. The relevant variables for this experiment are animacy, word order, and agreement. Again, it is hypothesized that children with or without impairment proceed from local to distributed cues; see (H1 G). Due to ambiguous case marking on the determiners, however, it was hypothesized in (H3 TD) and (H3 SLI) that children will turn from 
animacy to the positional strategy "first NP" before they orient toward agreement.

4.2.1. The findings for the typically developing participants. Again an overview of the groups' performance is given in Figure 4, which summarizes the contribution of each variable to homogeneity. Animacy is the most important factor for the youngest group (here the three-year-olds), ${ }^{19}$ but it has lost its relevance by age five. Word order contributes to homogeneity at up to about $39 \%$ with the three- and six-year-olds but then loses its influence. Agreement on the other hand contributes about $50 \%$ with the five-year-olds and is the only interesting factor for the eight-year-olds. The results of the logit analysis are summarized in Table 3. As in the previous experiment, the two types of analysis confirm each other. ${ }^{20}$

Again, the second set of tree-based analyses provides details about the behavior of the individual children within each age group. Proliferation in the trees starts again just above the terminal nodes.

For the three-year-olds the data can be grouped according to three criteria: according to animacy, according to the initial NP, and according to the "NP relative to the finite V." Six children orient toward animacy, four toward the initial NP, and two toward the NP closest to V. Thus,

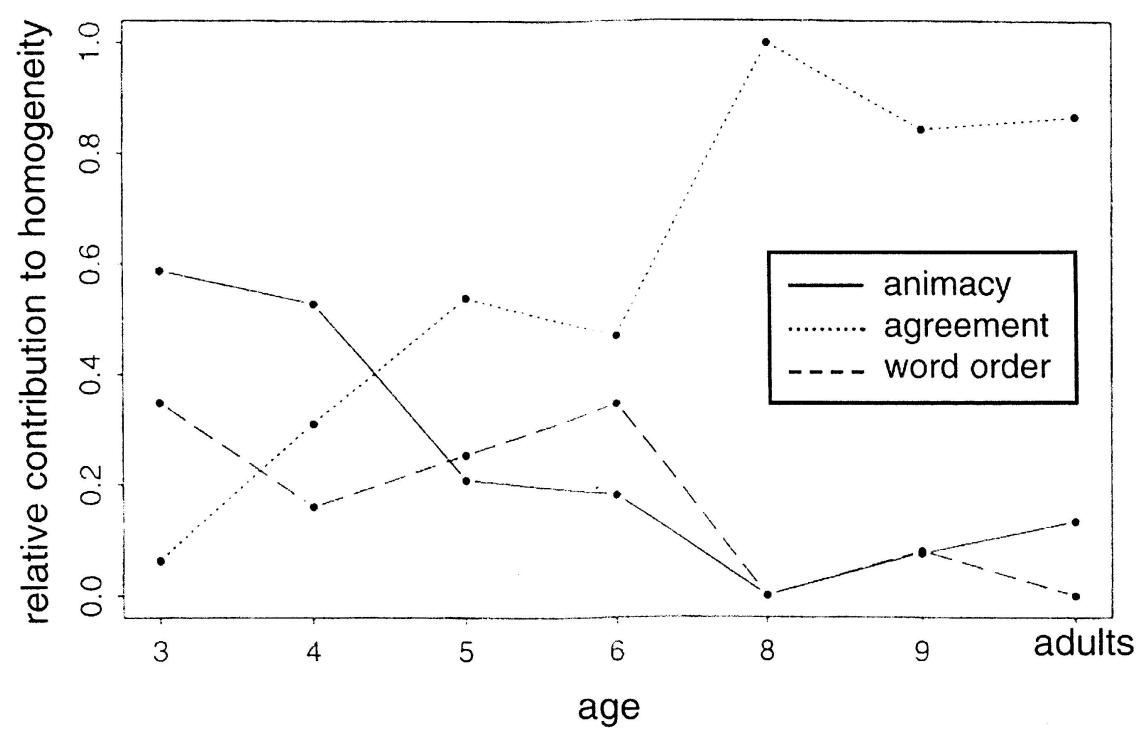

Figure 4. Relative contribution of animacy, agreement, and word order for all age groups of typically developing participants in experiment II 
Table 3. Results of the logit analysis for the typically developing participants in experiment II

\begin{tabular}{|c|c|c|c|}
\hline Age groups & Main effects & $\mathrm{F}$ & $\mathrm{p}$ \\
\hline 3-year-olds & animacy & $\mathrm{F}(2,436)=17.58$ & $\mathrm{p}<0.001$ \\
\hline 4-year-olds & $\begin{array}{l}\text { animacy } \\
\text { animacy } \times \text { agreement } \\
\text { animacy } \times \text { word order }\end{array}$ & $\begin{array}{l}\mathrm{F}(2,534)=5.27 \\
\mathrm{~F}(6,534)=2.99 \\
\mathrm{~F}(6,534)=1.99\end{array}$ & $\begin{array}{l}\mathrm{p}<0.001 \\
\mathrm{p}<0.001 \\
\mathrm{p}<0.1, \text { n.s. }^{\mathrm{a}}\end{array}$ \\
\hline 5-year-olds & agreement & $\mathrm{F}(2,635)=8.40$ & $\mathrm{p}<0.001$ \\
\hline 6-year-olds & $\begin{array}{l}\text { agreement } \\
\text { word order } \\
\text { animacy }\end{array}$ & $\begin{array}{l}\mathrm{F}(2,609)=16.19 \\
\mathrm{~F}(2,609)=6.94 \\
\mathrm{~F}(2,609)=3.35\end{array}$ & $\begin{array}{l}\mathrm{p}<0.001 \\
\mathrm{p}<0.001 \\
\mathrm{p}<0.05, \text { n.s. }\end{array}$ \\
\hline 8-year-olds & agreement & $\mathrm{F}(2,645)=61.98$ & $\mathrm{p}<0.001$ \\
\hline 9-year-olds & $\begin{array}{l}\text { agreement } \\
\text { animacy } \\
\text { word order }\end{array}$ & $\begin{array}{l}\mathrm{F}(2,633)=38.42 \\
\mathrm{~F}(2,633)=8.84 \\
\mathrm{~F}(2,633)=4.68\end{array}$ & $\begin{array}{l}\mathrm{p}<0.001 \\
\mathrm{p}<0.001 \\
\mathrm{p}<0.01, \text { n.s. }\end{array}$ \\
\hline Adults & $\begin{array}{l}\text { agreement } \\
\text { agreement } \times \text { animacy }\end{array}$ & $\begin{array}{l}F(2,639)=390.83 \\
F(6,639)=15.81\end{array}$ & $\begin{array}{l}\mathrm{p}<0.001 \\
\mathrm{p}<0.001\end{array}$ \\
\hline
\end{tabular}

a. n.s. $=$ not significant.

while animacy is still a very important cue (for $50 \%$ of the children), it appears that the three-year-olds are starting to take note of positional cues - the initial NP as well as the "NP relative to the finite V." As for the four-year-olds, there are only three children who rely heavily on animacy; one of them orients exclusively toward the animate NP. All other children choose the initial NP.

For the first time in this experiment, agreement is acknowledged by the five-year-olds (cf. the findings in experiment I). Two out of twelve children clearly prefer this cue when it points to the first or to the second NP (AG1 and AG2). All other children take the initial NP. Among the six-year-olds the number of children who prefer agreement rises to three; this tendency is stronger for agreement with the initial NP than with the second NP. Three other children orient toward the initial NP in combination with agreement (AG1) and word order, more so with NVN and VNN and randomly in the case of NNV. For six children the initial NP is the only cue they choose, independently of word order. This picture changes with the eight- and nine-year-olds. Progress can best be observed with agreement pointing to the second NP (AG2). The number of eight- 
year-olds orienting toward agreement with this NP rises to five and to seven among the nine-year-olds, and, finally, includes all adults.

Clearly, in the second experiment positional cues play a more important role than in the first experiment. Thus, four three-year-old children orient toward the initial NP; this number increases to nine with the four-yearolds and to ten among the five-year-olds and decreases to six among the six-year-olds (with three others showing some tendency) and to seven and five among the eight- and nine-year-olds. The "NP relative to the finite V" is acknowledged by two three-year-olds and by three six-yearolds. Thus some structural precursor for agreement seems to appear by age three. A reliance on agreement with the first or second NP, however, starts out gradually at age five with two children, rises to three with the next age group, to five with the eight-year-olds, and to seven among the nine-year-olds and is the most important cue for the adults. Thus, support is found for the general hypothesis $(\mathrm{H} 1 \mathrm{G})$ and for its specification in $(\mathrm{H} 3$ TD) that, in case of ambiguous case marking, children orient first toward animacy, then toward positional cues, and then toward agreement.

4.2.2. The findings with the impaired children. Once case distinctions are neutralized, the picture for the impaired children changes dramatically; see Figure 5. The two younger age groups rely exclusively on lexical

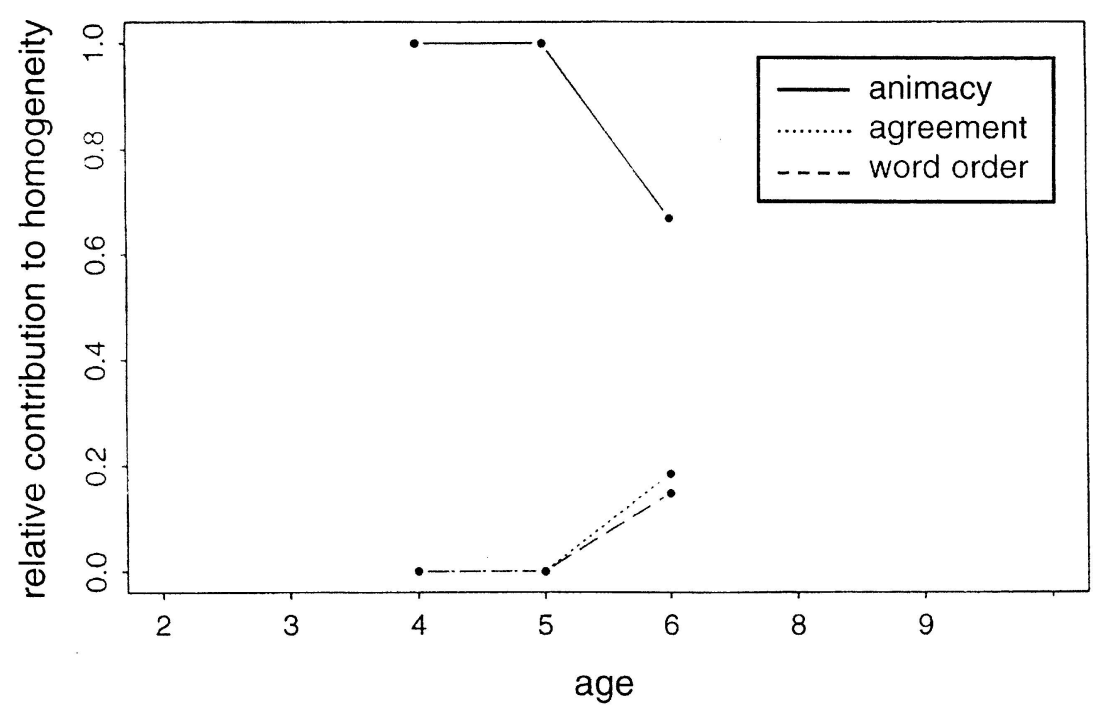

Figure 5. Relative contribution of animacy, agreement, and word order for all age groups of language-impaired children in experiment II 
semantics. Only the six-year-olds show some influence of word order and agreement. See Table 4 for the results of the logit analysis, which again confirm the results from the first set of tree-based analyses for the group data. The second set of tree-based analyses shows more details about the children's behavior.

Among the four-year-olds there are three children who choose the animate NP independent of its position. Three other children take the animate noun if it is the initial NP but are undecided when animacy is in coalition with the second NP (IA). One child chooses the initial NP exclusively. This child is severely impaired and chose this strategy likewise in experiment I.

Among the five-year-olds there are again three children who hold onto animacy; one (severely impaired) chooses the initial NP exclusively, and four others show a tendency for it $(60 \%$; three of these children are lightly impaired).

All six-year-olds take the initial NP if it is supported by animacy and agreement. But the group splits up into three subgroups when animacy is in coalition with the second NP (IA). Three children (one of them severely impaired) choose the initial NP independently of any other cue. The other five (three of them severely impaired) show some interaction of word order and animacy: they prefer the first, the inanimate NP, in NVN but take the second, the animate NP, in NNV and VNN. Thus in NVN and NNV these children also happen to choose the NP closest to V.

These findings show some progression from local to (more) distributed cues, from lexical semantics toward the grammatical cues, the initial NP, and, rather vaguely, the NP closest to the finite verb. Although agreement is not acknowledged as a single factor by the oldest children, ( $\mathrm{H} 1 \mathrm{G})$ may be said to be confirmed, since movement away from the local cue can be observed: both the initial NP and "NP relative to finite V" may

Table 4. Results of the logit analysis for the language-impaired children in experiment II

\begin{tabular}{llll}
\hline Age groups & Main effects & $\mathrm{F}$ & $\mathrm{p}$ \\
\hline 4-year-olds & animacy & $\mathrm{F}(2,317)=31.17$ & $\mathrm{p}<0.001$ \\
5-year-olds & animacy & $\mathrm{F}(2,372)=43.86$ & $\mathrm{p}<0.001$ \\
& $\begin{array}{l}\text { animacy } \\
\text { 6-year-olds }\end{array}$ & $\mathrm{F}(2,410)=15.71$ & $\mathrm{p}<0.001$ \\
& $\begin{array}{l}\text { animacy } \times \text { word order } \\
\text { animacy } \times \text { agreement }\end{array}$ & $\mathrm{F}(6,410)=3.50$ & $\mathrm{p}<0.005$ \\
& $\mathrm{~F}(6,410)=2.09$ & $\mathrm{p}<0.05$. $^{\text {n.s. }}{ }^{\text {a }}$ \\
\hline
\end{tabular}

a. n.s. = nonsignificant. 
be considered transient stages between local and distributed cues (cf. [5] in section 2.1).

However, not much support was found for the more specific hypothesis (H3 SLI) that the impaired children proceed from animacy to the initial NP to agreement. Animacy is the major cue for most four-year-olds and for three five-year-olds and is still relevant for the six-year-olds in combination with other cues, with agreement, the initial NP, or word order. The initial NP is chosen exclusively by one four- and one five-year-old, joined by four five-year-old peers who show some tendency for it $(60 \%)$. Thus it is noticeable in this age group. The number rises to three sixyear-olds in favor of the initial NP. Within this age group, too, "NP relative to the finite $\mathrm{V}$," a structural precursor of agreement, comes into play in the case of NVN and NNV. However, the question arises whether the relevant factor is animacy (as evidenced by NNV as well as in VNN) or whether it is structural proximity (as evidenced by NVN and by NNV). Despite some progress, agreement as predicted by (H3 SLI) is not reached.

4.2.3. Summary of the findings in experiment II: differences. The second experiment tested the variables animacy, word order, and agreement while case was neutralized. The performance of the typically developing children confirms the hypotheses (H1 G) and (H3 TD). These children evidence progression from local to distributed cues, from animacy to agreement, the latter cue coming into play again by age five. Clearly, when case is neutralized the positional strategy, "first NP," becomes quite important as a strategy leading from the lexical semantic cue to the morphosyntactic one. It is chosen already by four three-year-olds. This number rises to nine in the next age group, reaches ten with the fiveyear-olds, and then gradually decreases again with the older groups. Among the nine-year-olds there are still five children who prefer the initial NP in conflict with agreement. More complex structures, like the choice of the "NP relative to the finite V," are already noted by two three-year-olds and later by three six-year-olds (with a preference for the initial NP and agreement in NVN and VNN).

The general hypothesis $(\mathrm{H} 1 \mathrm{G})$ that children will move from local to distributed cues is also confirmed for the impaired children. However, they do not show the progression from animacy via the positional cue "first NP" up to agreement as specified in the hypothesis (H3 SLI). The majority of the four- and five-year-old children rely on animacy or the initial NP as the cue to the agent. Animacy is still an important cue for the oldest group: an animate initial NP in coalition with agreement is preferred by all of them; an animate second NP is preferred by five 
children in NNV and VNN. Only in NVN is the decision made independently of animacy. In NVN and NNV, in addition, the chosen NP is identical with the one closest to the finite verb. Thus there is some development among the impaired children. However, when we compare the findings for the two experiments, the impaired children clearly do not do as well with sentences with neutralized case as they do in the first experiment with unambiguous case markers. The results of experiment II show differences between the impaired and unimpaired groups of children, the major one being that animacy is relied on as a cue to agency even at the later ages among the children with SLI.

\section{General discussion}

\subsection{Summary of the findings}

This paper reports on findings in two experiments about the development of sentence-interpretation strategies in German-learning children without and with language impairment. Three hypotheses were tested. The general hypothesis $(\mathrm{H} 1 \mathrm{G})$ that children progress from local to distributed cues was confirmed. The other hypotheses specify the sequence to be observed in the two experiments. For experiment I with unambiguous case markers it was hypothesized ([H2 TD], [H2 SLI]) that children start with animacy before turning to the nominative and then to agreement, while for experiment II with ambiguous case markers ([H3 TD] [H3 SL]) the predicted transient phase between animacy and agreement is the positional strategy, "first NP."

The order predicted in (H2 TD) is confirmed for the typically developing children. Children first rely on animacy. At age four the nominative is acknowledged, but it is of interest in coalition predominantly with the initial NP, for older children also in support of agreement. Agreement is first seen in five-year-olds and gradually becomes the most important cue for the older children and the adults.

The impaired preschoolers also show a developmental trend. However, no support was found for the predicted order in (H2 SLI). These children, too, first orient toward animacy. However, instead of the transient stage with the cue nominative, both five- and six-year-olds seem to take note of the nominative and agreement at about the same time. It is only a subgroup of the six-year-olds that notices the nominative on the second NP. Generally speaking, the second and third phase of the predicted order seem to be mixed into one. 
For experiment II it was predicted in (H3 TD) that in the transient stage from animacy to agreement children switch to a "first-NP" strategy. This sequence is confirmed for the typically developing children. Moreover, some indication of a syntactic precursor of agreement, more complex syntactic structures with NP relative to the finite verb, is seen already in some three-year-olds. Agreement again is first observed among five-year-olds.

This same sequence as postulated in (H3 SLI) for the impaired children is not observed. They orient first toward animacy and then move on to relying on the initial NP and to some extent to more complex structures like "NP relative to the finite V." Yet agreement does not play the same role as it does with the nonimpaired peers and also when compared to their own performance in experiment I. In that experiment the impaired six-year-olds are able to make use of agreement, particularly if it is in coalition with the nominative. Thus case distinctions seem to provide supportive background information that is, of course, lacking with ambiguous case markers. Consequently when case is neutralized, the impaired children rely on or, rather, return to coalitions with more or less local cues like animacy or the initial NP. ${ }^{21}$

With these findings a number of issues arise of which only a few can be addressed here:

i. How do the findings in the two experiments relate to those of the standardized sentence-comprehension test, which all children from age three onward passed (cf. section 3.2.)?

ii. How do these findings relate to previous findings on typically developing children by Mills (1977) and Schaner-Wolles (1989)?

iii. How relevant is short-term memory for the findings of these experiments?

iv. What is the relationship between production and comprehension of case markers and agreement?

\subsubsection{Disparity in the results of the experiments and the standardized} sentence-comprehension test. The first issue concerns the relationship between the findings of the two experiments and the results of the standardized sentence-comprehension test, test A of the LSVT. As mentioned in section 3.1 all children from age three onward earned scores within normal range. Therefore, according to this standardized test, none of the impaired children was considered to have difficulties in sentence comprehension. ${ }^{22}$ However, children's performance may be influenced by the following factors: the events chosen in this test are of the everyday kind (cf. Appendix). Thus children may rely on world knowledge or event probability to supplement deficits in their linguistic knowledge. Furthermore, the 
setting and the figures remain constant for all events throughout the test, which again facilitates children's performance. Crucially, this standardized test examines children's performance with regard to phrase structure, passive constructions, and, above all, the sequencing of state of affairs. Thus, it does not examine morphosyntactic markers in particular detail, unlike the two experiments reported in this paper. Therefore the testing of sentence comprehension in future diagnoses ought to be supplemented by further examinations of morphosyntactic markers in order to arrive at a more precise evaluation.

5.2.2. The NP in initial position. The current study confirms previous findings by Mills (1977) and Schaner-Wolles (1989) that typically developing German-learning children at age five are able to recognize the unambiguous accusative in initial position. Schaner-Wolles showed that five-year-olds are correct in $89 \%$ of the items, while four-year-olds only reach $62 \%$. However, these children achieved higher scores than those who participated in the two experiments reported here. One reason for this difference may be a methodological one: Schaner-Wolles had asked her subjects to select the picture appropriate to the sentence they had heard instead of having them act it out. Thus in the current study children had to rely on auditory information only.

With regard to the processing of ambiguous case markers a "first-NPas-agent" strategy was suggested by Mills (1977) and Slobin (1981). In the study reported here there are only two children who choose the initial NP independent of other cues in both experiments (one typically developing and one severely impaired child). Thus, this strategy holds only for a tiny minority among the participants. Moreover, it is not restricted to the processing of ambiguous case markers.

Overall, the participants choose the initial NP in experiment II more often than in experiment I: among the typically developing children there is an increase from age three to six and a decrease to age nine and to the adults; among the impaired children the number rises from one to five at age five. Instead of the "first-NP-as-agent" strategy SchanerWolles (1989) suggested a pragmatic strategy, "subject first." She maintains that when by age three German-learning children are able to handle the distribution of the finite verb they also know that the initial position is not reserved for the subject. Since thematic roles are mapped onto morphological cases, word order is free to fulfil pragmatic needs. In the absence of unambiguous morphological indicators, children turn to the initial NP, thus relying on the unmarked word order in German. The initial NP in unmarked order may present not only the subject but also the topic the sentence is about. Recent findings from production data 
show that two-year-old children are able to mark the topic in initial position (by scope particles as a precursor to the finite verb in second position; cf. Nederstigt 2001; Jordens 2002); furthermore, there is comparable evidence from children with SLI (Lindner 2002). Thus, if case marking provides no clue to the agent then the initial NP may - perhaps even automatically - be chosen to be the topic. ${ }^{23}$ However, such an argument - which no doubt is quite plausible - presupposes a close relationship between production and comprehension skills; that is, if the children are able to mark the topic in production, they should also recognize it in the interpretation of sentences. We will return to this issue in section 5.2.4.

If this relationship is not as close as supposed, then there is still another possible interpretation that may be taken into account: Alongside the "first NP" strategy, an indication for another positional strategy - "NP next to finite verb" - was found to play some role for subgroups from age three to six for the unimpaired children and for the five- and sixyear-old impaired children. It builds on structural proximity. This finding may suggest that children in the transient stage from animacy to agreement move via a phase of structural cues, which in case of unambiguous case marking is hidden behind the nominative in first position and thus "does not show." This alternative interpretation does not necessarily preclude the (more or less automatic) assignment of topic to the initial NP suggested above. They may both "exploit" (roughly) the same structures. Clearly, more specific experiments are needed to resolve this issue. ${ }^{24}$

5.2.3. The findings and the results of the short-term memory test: cue cost. As mentioned in section 2 the competition model assumes that language learners are sensitive to the statistical properties of the language to be learned. In processing, learners not only perceive the information value of a particular cue in pointing at a particular function but they continually update the associations between forms and functions. The most valid cue is learned with greatest ease. However, as was shown in section 2.1 , cue validity may be impeded by cue cost, for instance by low perceptual salience of a cue or too large a load for the short-term memory to process. Agreement was considered to be a cue in German that is difficult to process since a number of constituents have to be compared before it can be evaluated. Thus, according to this account, children who have relatively poor short-term memory, such as younger typically developing children, should also have more problems with using agreement as a cue to agent interpretation than do children with better short-term memories. 
There has been considerable discussion about verbal short-term memory limitations as a source for the difficulties of language-impaired children, especially as tested by list recall of one-syllable words (e.g. Gathercole and Baddeley 1990; van der Lely and Howard 1993; Howard and van der Lely 1995). Thus, if the language-impaired children in the current study do show evidence of poor short-term memories, this might account for their difficulties in using agreement as a cue relative to their normally developing peers.

All participants aged two to six received a short-term memory test, the results of which were shown in Figure 1. Clearly the typically developing children show a definite increase in memory span, from two to almost four items for the group data (up to five items for individual five- and six-year-olds), while the memory span for the impaired children is rather low. The lightly impaired children achieve a range of 1.5-2 items for the four-year-olds, 2-3 for the five-year-olds, 2.5-4 for the six-year-olds; the severely impaired children achieve a range of 1.5-3 for the four-yearolds, 1.5-3.5 for the five-year-olds, and 2-3.5 for the six-year-olds. Therefore in terms of group scores, there does seem to be some indication that difficulties in using agreement as a sentence-interpretation cue might be linked to poor short-term memory. However, there is no $1: 1$ correspondence comparing individual performances on language and shortterm memory tests. To cite just a few examples of five-year-olds: a fiveyear-old severely impaired child who is able to detect the accusative in first position remembers three to four items correctly; that is, her shortterm memory is quite good. Yet, a lightly impaired boy whose performance is even better than hers only recalls two to three items correctly. On the other hand, the typically developing children who acknowledge the accusative in initial position are all able to remember four items, while those who prefer the initial NP are only correct with three items. Thus, simple direct comparisons may not be helpful. The short-term memory test used for the participants in the current investigation is too crude to have any explanatory power. Yet it seems to be worthwhile to pursue this perspective. ${ }^{25}$

Last, it should be noted that agreement may be difficult to process only when it involves a memory burden, as in the sentences with transitive verbs used in the current study. If agreement can be interpreted "on the spot" this may pose no difficulties as a cue to sentence interpretation. Devescovi et al. (1998) have explored the use of person marking on verbs with young Italian children. They found that two-year-olds are able to notice the markers for the first and second person singular. Thus if agreement can be interpreted locally, children may be able to utilize that information well before age five. This finding supports the notion of cue 
cost because of short-term memory constraints, that is, children may have the knowledge about particular linguistic markers but cannot make use of them due to processing costs.

This leads us to the last issue to be addressed here: the relationship between children's skills in producing and interpreting sentences.

5.2.4. Asynchrony in children's production and interpreting skills. The findings of the two experiments show that, in typical development, children start out with lexical semantics, animacy and then proceed to grammatical cues, such as the nominative, the first NP, or agreement. Agreement comes in at age five. Possible structural precursors like the "NP relative to the finite verb" can already be observed at age three.

Production data from the same typically developing children show, however, that children at age two to three are able to establish agreement between the subject and the finite verb. Moreover, in production, case marking is acquired later than agreement. Thus the sequence observed in the investigation reported here is just the opposite of the sequence found in the production data. To be more precise: all except one child of the two-year-olds participating in the first experiment were able to consistently establish agreement in spontaneous speech and in experimental situations (using both one- and two-place predicates, cf. Lindner n.d.). However, case markers (i.e. the contrast between nominative and accusative, along with a few datives) were produced by ten out of twelve twoyear-olds (all girls and four boys). If production and interpretation of these devices were to be acquired in synchrony, all of these children should be able to make use of agreement in the sentence-interpretation task.

Various reasons come to mind as to why there is a delay in the exploitation of agreement markers. One reason is processing costs, as mentioned in the previous section. Thus the typically developing children may be able to utilize agreement as a local cue much earlier. It is only in sentences of the sort presented in these experiments - with a transitive verb and two full NPs - that agreement as a sentence-interpretation cue presents difficulties for children under five.

A second reason may have to do with another aspect of the design of the experiments. The sentences participants heard were not embedded into any particular context that could be relied on. A third reason may be that these experiments were off-line. Thus children had some limited time to react. Most of them responded spontaneously. However, there were also a few children who seemed to "think" about the sentences they heard. For them this tended to become a problem-solving situation, ${ }^{26}$ a metalinguistic task, which at age two to four or five may be difficult 
to solve for normal children, let alone for children with more limited linguistic skills.

Another issue is the validity of inferences about children's linguistic knowledge based on production data. Children may be able to produce $\mathrm{x}$ but not to understand it (or only to understand parts of it) or the other way around (e.g. Chapman and Miller 1975). This asynchrony can be observed easily with first- and second-language learners in everyday life. In addition, in spontaneous production, children may initially be using patterns of limited scope without being able to generalize them; that they build up knowledge about language gradually has been discussed for some time (e.g. Chapman 1992; Tomasello 2000). Thus production data at an early age may not be a reliable indicator of children's linguistic knowledge. ${ }^{27}$

If this situation holds for typically developing children, it also holds for language-impaired children. Even if most of the lightly impaired children use agreement and case markers, this does not imply necessarily that they are able to utilize this information in sentence interpretation. The situation is even more complicated with severely impaired children. Some of them mark case distinctions without marking agreement, others start on agreement but keep the verb in last position and mark or do not mark case. Detailed comparisons are needed of children's production and comprehension data, including information about prosodic properties, in order to find out more about the relationship between producing and interpreting sentences.

This paper provided a few pieces to the complex puzzle of language processing and acquisition, in examining sentence-interpretation strategies in children with and without language impairment. On the basis of the current study, we can clearly say that both impaired and unimpaired German children do progress from local to more distributed cues for their interpretation of the agent. More specifically, they initially rely on animacy and only later on start to make use of the grammatical cues of case marking, word order, and subject-verb agreement, with the latter being the most difficult in sentences with a transitive verb. Yet there is evidence that language-impaired children differ in their choice of cues from their typically developing peers. However, it is still too early to decide whether these findings support an interpretation of delayed or deviant development in children with SLI. Further research is necessary to explore in more detail the cost of processing particular cues in children with and without language impairment.

Received 29 May 2001

Universität München

Revised version received

28 May 2002 


\section{Appendix. Sentences of the LSVT Part C (Wettstein 1983)}

1. Die Mutter geht zum Baum.

'The mother goes to the tree.'

2. Der Vater steigt ins Auto.

'The father climbs into the car.'

3. Das Mädchen wird vom Bub umgeworfen.

'The girl is knocked down by the boy.'

4. Der Ball wird vom Bub versteckt.

'The ball is hidden by the boy.'

5. Der Bub rennt mit dem Hund zum Baum.

'The boy runs together with the dog to the tree.'

6. Der Bub spielt mit dem Hund.

'The boy plays with the dog.'

7. Der Vogel fliegt auf den Turm und dann auf das Hausdach.

'The bird flies up to the tower and then to the roof of the house.'

8. Das Mädchen holt den Ball und bringt ihn dem Hund.

'The girl fetches the ball and brings it to the dog.'

9. Das Mädchen streichelt den Hund, bevor es nach Hause geht.

'The girl pats the dog before she goes home.'

10. Der Hund bellt, weil ihm der Bub den Ball weggenommen hat.

'The dog barks, because the boy has taken the ball away from him.'

11. Weil der Bub das Mädchen gehauen hat, muss er mit der Mutter ins Haus. 'Since the boy has hit the girl, he has to go home with the mother.'

12. Der Vater steigt aus dem Auto, ruft den Hund und macht mit ihm einen langen Spaziergang.

'The father leaves the car, calls the dog, and goes for a long walk with him.'

13. Während das Mädchen vom Turm heruntersteigt, fliegt der Vogel auf den Baum.

'While the girl climbs down from the tower the bird flies to the tree.'

14. Die Mutter umarmt den Vater und dann tanzen das Mädchen und der Bub. 'The mother embraces the father and then the girl and the boy dance.'

15. Alle, ausser dem Mädchen, suchen den Hund, der hinter den Turm gelaufen ist.

'Everyone except the girl searches for the dog who has run behind the tower.'

16. Das Mädchen kommt aus dem Haus und, nachdem es auf den Turm gestiegen ist, ruft es dem Vater laut zu: Huhu!

'The girl leaves the house and, after having climbed up to the tower, shouts to the father: huhu!'

17. Bevor die Mutter zum Auto geht, winkt sie dem Mädchen zu.

'Before the mother goes to the car, she waves to the girl.'

\section{Notes}

* The data for this study were collected in the project "Funktionale Determinanten im Spracherwerb" directed from 1990-1992 by Prof. Dr. Rolf Castell — Az. CA 50/6-1 — 
and from 1992-1994 by Prof. Dr. Elmar Seebold — Az. Se 249/4-2 — and funded by the Deutsche Forschungsgemeinschaft. I would like to thank my colleagues who collaborated in collecting the comprehension and production data and analyzing and discussing it with me: Christina Schelletter, Kerstin Täubner, and Sabine Stoll. Special thanks to Elizabeth Bates, Antonella Devescovi, and Brian MacWhinney, who discussed the construction of the stimuli of experiment I with us. Elizabeth Bates and Angela Friederici were so kind as to let us use the stimuli of their cross-linguistic experiment with aphasics in 1987; Angela Friederici allowed us to use the plastic objects to act out the sentences. Special thanks also to Harald Baayen, who first introduced me to treebased analyses and did the statistical analyses. Reports on parts of this investigation have been presented at the Child Language Seminar 1991 in Manchester, at the International Conference "Crossing Boundaries" 1991 in Tübingen, at the DFGSchwerpunkt-Tagung at Düsseldorf 1993, at the 15th Symposium on Research in Child Language Disorders in Madison, Wisconsin, in 1994, at the Zentrum für Allgemeine Sprachwissenschaft in Berlin in 1998. Thanks to all discussants for their comments and suggestions. For very constructive comments on earlier versions of this paper I thank Ursula von Benda, Brian MacWhinney, and two anonymous reviewers. Last but not least I am grateful to Kirsten Abbot-Smith and Phil Hoole for checking my English. Of course, any remaining errors are mine. Correspondence address: Institut für Deutsche Philogie, Universität München, Schellingstr. 3, D-80799 München, Germany. E-mail: katrin.lindner@germanistik.uni-muenchen.de.

1. Schaner-Wolles investigated various kinds of passive sentences as well as OVS structures with either an accusative or a dative. Passives were recognized by three-year-old children. The only construction where children resorted to the first NP as agent was in passives without an agentive phrase like Die Mutter wird geküßt 'The mother is being kissed'.

2. In comprehension tasks of the kind described above, Thal and Flores (2001) found that late talkers who were delayed in their language development about six months did not orient toward either animacy or word order by age 2;6 while their typically developing peers used animacy in coalition with word order. By age three both groups made use of word order. Although the late talkers showed a different start, at least the subjects in this study seem to have caught up with normal development.

3. Availability is not to be confused with frequency. Availability of a cue in the sense referred to here is only relevant in pointing to a particular function (e.g. agent). For example animacy cues do not refer to the frequency of animate nouns in a sentence but only to those cases where animacy is contrastive, i.e. one noun is animate and the other is inanimate (cf. Kempe and MacWhinney 1998: 550).

4. A change in word order, of course, is context-dependent and thus may also change the position of the focus accent. Quite often the focus is on the nominative (cf. for instance [3b]) while the topicalized accusative may receive contrastive stress (cf. [3b]). The two possible positions of the accent in ( $3 b$ ) are best translated into English cleft sentences.

5. The finite verb in final position is better known from embedded sentences introduced by a complementizer, as the next sentence shows:

(i) Ich glaube, dass der Mann den Hund gestreichelt hat.

I think that the man the-ACC dog patted has

'I think that the man has patted the dog.'

If the complementizer is missing then the finite verb moves into second position. $\mathrm{Cf}$. the following sentence: 
(ii) Ich glaube, der Mann hat den Hund gestreichelt. I think the man has the dog patted. 'I think that the man has patted the dog.'

6. Recall that cue validity is computed by multiplying the availability and the reliability of that cue. Availability in turn is calculated as the ratio of the number of instances where the cue is present divided by the total number of transitive sentences; reliability is computed as the ratio of the number of instances where a cue correctly points to the agent divided by the number of cases where it is present. Another text count is currently under way calculating the reliability of cues in the input data from parents addressing their two-year-olds.

7. Cf. the hypothesis about "missing agreement" by Clahsen (1991) as well as his findings for case. Yet German children are also known for their problems with the position of the finite verb; cf. e.g. Grimm and Weinert (1990). For a discussion cf. Hamann et al. (1998) and Lindner (2002).

8. Cf. e.g. Bishop (1992), Johnston (1988). For German-learning school children cf. Schöler et al. (1998); for a deviance view on young impaired children cf. Penner et al. (1999) as well as Penner et al. (this issue).

9. The inclusion of nine-year-olds was suggested by Elizabeth Bates and Antonella Devescovi (personal communication). They had found that Italian nine-year-olds utilize agreement in a manner similar to Italian adults. Cf. Devescovi et al. (1998).

10. The norms of this test are rather soft and they start for four-year-olds. In order to be sure that none of the SLI children had a comprehension problem the threshold was set at the 69 th percentile.

11. This test is an adaptation of the Sklar (1973) by H. Amorosa and U. von Benda (formally Max-Planck-Institut für Psychiatrie, Munich). The subjects are asked to listen to the sequence of names of objects and then point to them, starting with two items, then three and four up to five. The objects are named with an interval of half a second in between. All names of the objects were either monosyllabic (CCVCC) or bisyllabic ('CVCV $(\mathrm{C})$ ) thus following the dominant prosodic trochaic pattem in German: Stift 'pencil, Knopf 'button', Schachtel 'box', Löffel 'spoon', Gabel 'fork', Nagel 'nail', Messer 'knife', Tasse 'cup', Puppe 'doll', Flasche 'bottle', Schere 'scissors'. Each child was first asked to name all objects in order to make sure that they knew the name. Amorosa and von Benda used this adaptation with children who are not able to count correctly up to ten. Given that children with SLI have difficulties with numbers (cf. Fazio 1994) this test is particularly useful for all preschool children in the study. Werner (1989) has shown that the results of this test correlate strongly with the digit span test of the German version of the ITPA (the Psycholinguistische Entwicklungstest by Angermaier 1973), a test often employed in German diagnostic centers to measure short-term memory.

12. The term "case" (abbr. C) is used here as a cover term, although in general only casus obliqui are subsumed under this term. In sentences with a transitive verb the accusative - the casus obliqui - is always present, so that the term - used to cover $\mathrm{C} 1, \mathrm{C} 2$, or $\mathrm{C} 0$ - may be justified. The reason to include the nominative was, furthermore, that a distinction between the nominative and the first NP was necessary.

13. This holds also for the interactions of variables provided in Table 1-Table 4 (which are also present in both sets of tree-based analyses). For the most part these interactions will not be examined in greater detail in the remainder of this paper unless they play a role in the individual performance. For comparisons cf. Lindner (n.d. chapter 2).

14. For the analysis in full detail see Lindner (n.d. chapter 2). 
15. In this age group (as well as with the eight-year-olds) case is the first and thus dominant variable to classify the data in both types of tree-based analyses, for the group and the individual data. In all other age groups the first variable is either animacy or agreement.

16. For further findings about the behavior of German-speaking adults in cross-linguistic comparisons, cf. MacWhinney et al. (1984) and Kempe and MacWhinney (1998, 1999). The latter studies point out that compared to Russian speakers German speakers profited less from case marking and more from animacy in on-line sentence interpretation. Animacy was also found to be a major cue for German adults in comparison with English and Italian adults (cf. MacWhinney et al. 1984); however, this off-line experiment did not consider case as a variable. In the current study, animacy only played a minor role in experiment II.

17. With regard to the three-year-olds the relevant conflict would be between the initial NP and an animate second NP. The majority of children in this age group, however, are undecided ( $54 \%$ in favor of the first NP; see above).

18. Recall that three of the four six-year-olds who decide in favor of $\mathrm{C} 2$ in the competition of AG1 vs. C2 are severely impaired children. Thus the degree of severity may be one factor to be taken into account. For a more extensive discussion cf. Lindner (n.d.).

19. The two-year-olds only participated in experiment I. Participation in both experiments would have been too strenuous for them.

20. As in experiment $I$ the interactions provided in the tables will not be explored in further detail (cf. note 13) unless they are of importance to the individual performance reported here.

21. Note that the differentiation of word orders observed among the six-year-old impaired children in experiment II is different from that found for the impaired five-year-olds in experiment I or for the three- and six-year-old normal children in experiment II. This too, may be an indication of children's irritation.

22. For similar findings with toddlers cf. Thal and Flores (2001).

23. This may also be a plausible interpretation for the two children who take the initial NP in both experiments.

24. Of particular interest in this regard are studies based on ERPs; cf. Sabisch et al. (2002).

25. Booth et al. (2000) have shown that there are good correlations for short-term memory tests (digit span and reading span) and the comprehension of complex sentences in schoolchildren. With regard to children with SLI, the type of information may play a role as well: a recent study based on ERPs has found that the processing of acoustic information was more strenuous for them than the processing of visual information; cf. Glass et al. (2002).

26. Evidence is provided by children's self-addressed utterances and by repairs or requests for clarification.

27. This holds only if linguistic knowledge is assumed to be the same for both production and comprehension. The situation changes if production and comprehension are separated, as has been discussed with regard to the lexicon; cf. Menn and Matthei (1992).

\section{References}

Ammon, Mary S.; and Slobin, Dan I. (1979). A cross-linguistic study of the processing of causative sentences. Cognition 7, 3-17.

Angermeier, Michael (1973). Psycholinguistischer Entwicklungstest. Weinheim: Beltz.

Bates, Elizabeth; Friederici, Angela; and Wulfeck, Barbara (1987). Comprehension in aphasia: a cross-linguistic study. Brain and Language 32, 19-67. 
-; and MacWhinney, Brian (1982). Functionalist approaches to grammar. In Language Aquisition: The State of the Art, Eric Wanner et al. (eds.), 173-218. Cambridge: Cambridge University Press.

-; and MacWhinney, Brian (1989). Functionalism and the competition model. In The Cross-Linguistic Study of Sentence Processing, Brian MacWhinney et al. (eds.), 3-73. Cambridge: Cambridge University Press.

-; MacWhinney, Brian; Caselli, Christina; Devescovi, Antonella; Natale, Francesco; and Venza, Valeria (1984). A cross-linguistic study of the development of sentence interpretation strategies. Child Development 55, 341-354.

Bishop, Dorothy V. M. (1979). Comprehension in developmental language disorders. Developmental Medicine and Child Neurology 21, 225-238.

- (1982). Comprehension of spoken, written and signed sentences in childhood language disorders. Journal of Child Psychology and Psychiatry 23, 1-20.

-(1992). The underlying nature of specific language impairment. Journal of Child Psychology and Psychiatry 33, 1-64.

-(1997). Uncommon Understanding. Development and Disorders of Language Comprehension in Children. Hove: Psychology Press.

Booth, James R.; MacWhinney, Brian; and Harasaki, Yasuaki (2000). Developmental differences in visual and auditory processing of complex sentences. Child Development 71, 981-1003.

Burgermeister, Bessie B.; Hollander Blum, Lucille; and Lorge, Irving (1972). Columbia Mental Maturity Scale, 2nd ed. New York: Harcourt Brace Jovanovich.

Chapman, Robin S. (1992). Processes in Language Acquisition and Disorders. St. Louis, MO: Mosby Year Book.

-; and Kohn, Lawrence L. (1978). Comprehension strategies in two- and three-year-olds: animate agents or probable events? Journal of Speech and Hearing Research 21, 746-761.

-; and Miller, Jon (1975). Word order in early two- and three-word utterances. Does production precede comprehension? Journal of Speech and Hearing Research 18, 355-371.

Clahsen, Harald (1991). Child Language and Developmental Dysphasia. Amsterdam: Benjamins.

Clark, Linda; and Pregibon, Daryl (1991). Tree-based models. In Statistical Models in S, John M. Chambers et al. (eds.), 377-419. Pacific Grove, CA: Wadsworth and Brooks/ Cole Advanced Books and Software.

Devescovi, Antonella; D'Amico, Simonetta; Smith, Stan; Mimica, Ivo; and Bates, Elizabeth (1998). The development of sentence comprehension in Italian and Serbo-Croatian: local versus distributed cues. In Sentence Processing: A Cross-Linguistic Perspective, Dieter Hillert (ed.), 345-377. Syntax and Semantics 31. San Diego and London: Academic Press.

Evans, Julia; and MacWhinney, Brian (1999). Sentence processing strategies in children with expressive and expressive-receptive specific language impairments. International Journal of Language and Communcation Disorders 34, 117-134.

Fazio, Barb (1994). The counting ability of children with specific language impairment: a comparison of oral and gestural tasks. Journal of Speech and Hearing Research 37, $358-368$.

Gathercole, Susan E.; and Baddeley, Alan D. (1990). Phonological memory deficits in language disordered children: is there a causal connection? Journal of Memory and Language 29, 336-360.

-; and Baddeley, Alan D. (1995). Short-term memory may yet be deficient in children with language impairments: a comment on van der Lely and Howard (1993). Journal of Speech and Hearing 38, 463-466. 
Glass, Lisa; Sabisch, Beate; and von Suchodoletz, Waldemar (2002). Untersuchungen der akustisch und visuell evozierten P300-Komponente bei sprachentwicklungsgestörten Kindern. Poster presented at the 2. Interdisziplinäre Tagung über Sprachentwicklungsstörungen, 5-6 April, Universität Postdam.

Grimm, Hannelore; and Weinert, Sabine (1990). Is the syntax development of dysphasic children deviant and why? New findings to an old question. Journal of Speech and Hearing Research 33, 220-228.

Hamann, Cornelia; Penner, Zvi; and Lindner, Katrin (1998). German impaired grammar: the clause structure revisited. Language Acquisition 7, 193-245.

Howard, David; and van der Lely, Heather (1995). Specific language impairment is not due to a short-term memory deficit. Response to Gathercole and Baddeley. Journal of Speech and Hearing Research 38, 466-472.

Johnston, Judith R. (1988). Specific language disorders in the child. In Handbook of SpeechLanguage Pathology and Audiology, Norman J. Lass et al. (eds.), 685-715. Toronto, Ontario: Decker.

Jordens, Peter (2002). Finiteness in early child Dutch. Linguistics 40(4), 687-765.

Kail, Michèle; and Charvillat, Agnes (1988). Local and topological processing in sentence comprehension by French and Spanish children. Journal of Child Language 15, 637-662.

Karmiloff-Smith, Annette (1985). Language and cognitive processes from a developmental perspective. Language and Cognitive Processes 1, 60-85.

Kempe, Vera; and MacWhinney, Brian (1998). The acquisition of case marking by adult learners of Russian and German. Studies in Second Language Acquisition 20, 543-587.

-; and MacWhinney, Brian (1999). Processing of morphological and semantic cues in Russian and German. Language and Cognitive Processes 14, 129-171.

Kiese, Christiane; and Kozielski, Peter-Michael (1979). Aktiver Wortschatztest für drei- bis sechsjährige Kinder. Weinheim: Beltz.

Lindner, Katrin (2002). Finiteness and children with specific language impairment. Linguistics 40(4), 797-847.

- (n.d.). Normale und gestörte Sprachentwicklung bei Kindern. Studien zum Verstehen und zur Produktion.

-; and Johnston, Judith R. (1992). Grammatical morphology in language-impaired children acquiring English or German as their first language: a functional perspective. Applied Psycholinguistics 13, 115-129.

MacWhinney, Brian (1987). The competition model. In Mechanism of Language Acquisition, Brian MacWhinney (ed.), 249-308. Hillsdale, NJ: Erlbaum.

-; and Bates, Elizabeth (eds.) (1989). The Cross-Linguistic Study of Sentence Processing. Cambridge: Cambridge University Press.

-; Bates, Elizabeth; and Kliegl, Reinhold (1984). Cue validity and sentence interpretation in English, German, and Italian. Journal of Verbal Learning and Verbal Behavior 23, $127-150$.

—; Bates, Elizabeth; and Pleh, Czaba (1985). Development of sentence interpretation in Hungarian. Cognitive Psychology 17, 178-209,

McDonald, Janet (1986). The development of sentence comprehension strategies in English and Dutch. Journal of Experimental Child Psychology 41, 317-335.

- (1989). The acquisition of cue-category mappings. In The Cross-Linguistic Study of Sentence Processing, Brian MacWhinney et al. (eds.), 375-396. Cambridge: Cambridge University Press.

Menn, Lise; and Matthei, Edward (1992). The "two lexicon" account in child phonology: looking back, looking ahead. In Phonological Development. Models, Research, Implications, Charles A. Ferguson et al. (eds.), 211-247. Timonium, MD: York. 
Mills, Anne (1977). First and Second Language Acquisition in German: A Parallel Study, Reinhard O. U. Strauch (ed.). Ludwigsburg Studies in Language and Linguistics 2. Ludwigsburg: R. O. U. Strauch.

Nederstigt, Ulrike (2001). The acquisition of additive "focus particles" in German. In Proceedings from the 25th Annual Boston University Conference on Language Development, Anne H. L. Do et al. (eds.), 554-565. Somerville, MA: Cascadilla.

O'Hara, Margaret; and Johnston, Judith R. (1997). Syntactic bootstrapping in children with specific language impairment. European Journal of Disorders of Communciation 32, 189-203.

Penner, Zvi; Wymann, Karin; and Schulz, Petra (1999). Specific language impairment revisited. Parallelism vs. deviance. Fachgruppe Sprachwissenschaft der Universität Konstanz Arbeitspapier 105, 1-26. Konstanz: Universität Konstanz.

Pinker, Stephen (1987). The bootstrapping problem in language acquisition. In Mechanism of Language Aquisition, Brian MacWhinney (ed.), 399-442. Hillsdale, NJ: Erlbaum.

Sabisch, Beate; Hahne, Anja; von Suchodoletz, Waldemar; and Friederici, Angela (2002). Syntaktische und semantische Sprachverstehensprozesse bei sprachentwicklungsgestörten Kindern (SES) untersucht anhand ereigniskorrelierter Potentiale (EKIP). Poster presented at the 2. Interdisziplinäre Tagung über Sprachentwicklungsstörungen, 5-6 April, Universität Potsdam.

Schaner-Wolles, Chris (1989). Strategies in acquiring grammatical relations in German: word order or case marking? Folia Linguistica 23, 131-156.

Schöler, Hermann; Fromm, Waldemar; and Kany, Werner (1998). Spezifische Sprachentwicklungsstörung und Sprachlernen. Heidelberg: Winter, Edition Schindele.

Sklar, Maurice (1973). Sklar Aphasia Scale, Revised. Los Angeles: Western Psychological Services.

Slobin, Dan I. (1981). The origins of grammatical encoding of events. In The Child's Construction of Language, W. Deutsch (ed.), 185-199. London and New York: Academic Press.

-; and Bever, Tomas (1982). Children use canonical sentence schemas: a cross-linguistic study of word order and inflections. Cognition 12, 229-265.

Strohner, Hans; and Nelson, Keith (1974). The young child's development of sentence comprehension: influence of event probability, non-verbal context, syntactic form and strategies. Child Development 45, 567-576.

Thal, Donna; and Flores, Melanie (2001). Development of sentence interpretation strategies by typically developing and late-talking toddlers. Journal of Child Language 28, 173-193.

Tomasello, Michael (2000). Do young children have adult syntactic competence? Cognition 72, 209-253.

van der Lely, Heather (1994). Canonical linking rules: forward versus reverse linking in normally developing and specifically language-impaired children. Cognition 51, 29-72.

-; and Harris, Margret (1990). Comprehension of reversible sentences in specifically language-impaired children. Journal of Speech and Hearing Research 55, 101-117.

-; and Howard, David (1993). Children with specific language impairment: linguistic impairment or memory deficit? Journal of Speech and Hearing Research 36, 1193-1207.

Veit, Sabine E.; and Castell, Rolf (1992). Sprachproduktion und Sprachverständnis bei dysgrammatisch sprechenden Vorschulkindern. Zeitschrift für Kinder- und Jugendpsychiatrie 20, 12-21.

Weist, Richard (1983). The word order myth. Journal of Child Language 10, 97-106.

Werner, Georg M. (1989). Untersuchung Kurzzeitgdächtnisstörungen in der Kinder- und Jugend psychiatrie. Unpublished dissertation, University of Munich.

Wettstein, Peter (1983). Logopädiseher Sprachverständnistest. Zürich: Heilpädagogisches Seminar. 